INSTITUTO LUTERANO DE ENSINO SUPERIOR ILES/ULBRA CURSO DE BACHARELADO EM ADMINISTRAÇÃO

GABRIELA ALVIM MOREIRA

GESTÃO RURAL: A IMPORTÂNCIA DA ADMINISTRAÇÃO NO DESENVOLVIMENTO DE PROPRIEDADES RURAIS 
GABRIELA ALVIM MOREIRA

GESTÃO RURAL: A IMPORTÂNCIA DA ADMINISTRAÇÃO NO DESENVOLVIMENTO DE PROPRIEDADES RURAIS

Trabalho de Conclusão de Curso apresentado ao Instituto Luterano de Ensino Superior de Itumbiara-GO para obtenção do título de Bacharel em Administração.

Orientadora: Sandra Marques Borges. 
Dados Internacionais de Catalogação na Publicação (CIP)

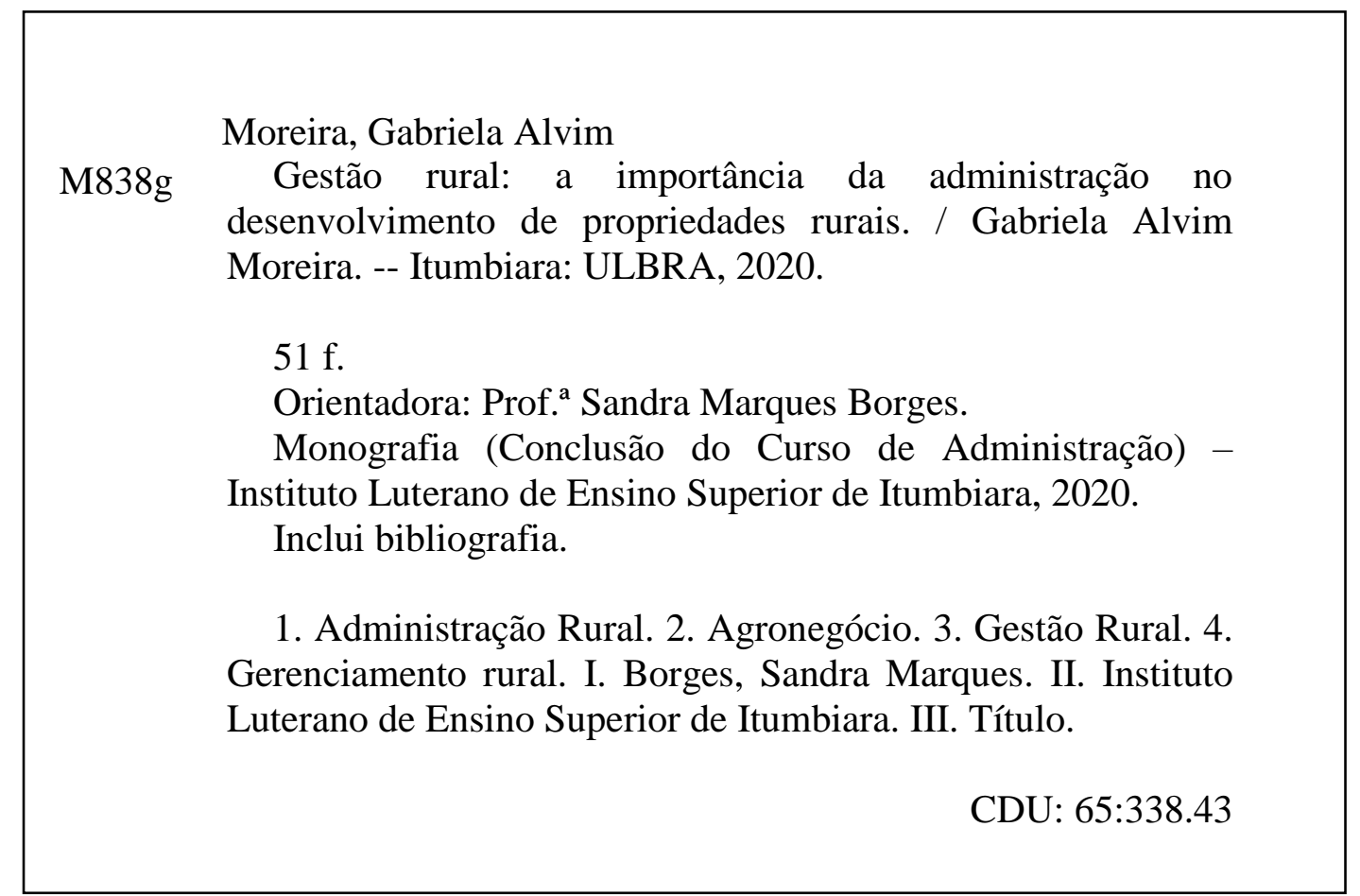

Bibliotecária Responsável: Janaína Cunha da Silva CRB/1 - 2902 


\section{GESTÃO RURAL: A IMPORTÂNCIA DA ADMINISTRAÇÃO NO DESENVOLVIMENTO DE PROPRIEDADES RURAIS.}

Trabalho de Conclusão de Curso submetido ao curso de Administração do Instituto Luterano de Ensino de ItumbiaraGoiás com a finalidade de obtenção do título de Bacharel em Administração.

Data de apresentação:

Nome

Titulação - Instituição

Nome

Titulação - Instituição

Nome

Titulação - Instituição 


\section{DEDICATÓRIA}

Dedico este Trabalho de Conclusão de Curso primeiramente a Deus. Aos meus familiares, principalmente minha mãe e meu pai, por sempre me apoiarem e me incentivarem nessa jornada. Ao meu namorado, que sempre me apoiou e me deu força para vencer as dificuldades durante a graduação. A minha orientadora Sandra Marques Borges que me auxiliou na germinação das ideias e durante todo o processo de desenvolvimento desta presente monografia. 


\section{AGRADECIMENTOS}

Agradeço primeiro a Deus por ter me mantido na trilha certa durante este trabalho de conclusão de curso com saúde e forças para concluí-lo. A meu irmão dedico agradecimento especial pelo apoio durante todo o processo. Aos meus pais por todo o esforço investido em minha educação. A todos os meus colegas do curso de graduação superior que compartilharam dos inúmeros desafios enfrentados, sempre com espírito colaborativo. A todos os mestres que me acompanharam e contribuíram com minha formação acadêmica nesses quatro anos. E à minha orientadora pelas valiosas contribuições dadas durante toda esta etapa. 


\section{RESUMO}

O presente trabalho discorreu bibliograficamente sobre as práticas de gestão das propriedades rurais, foco de estudo, a execução através da administração nessas propriedades facilitando para os produtores rurais na tomada de decisões para propriedades agrícolas, afim de obter melhores resultados econômicos e por consequência aumento dos lucros. O objetivo geral foi expor sistemas administrativos que cooperam para a melhoria significativa da gestão rural dentro das propriedades agrícolas. E os objetivos específicos constituem explanação sobre a potência que é o agronegócio no país, identificando os modelos de Gestão Rural com êxito em suas administrações e descrevendo as etapas a serem seguidas dentro da Gestão Rural.

No que tange às classificações da pesquisa foi aplicada a abordagem classificada como hipotético-dedutiva, quanto aos objetivos foi considerada exploratória e explicativa, quanto aos procedimentos classificou-se como bibliográfica descritiva e, por fim, a coleta de dados foi realizada através da documentação indireta. Os resultados obtidos constataram a importância da administração na gestão de propriedades rurais. Destarte, concluiu-se que, em conformidade com o que se pôde notar durante as pesquisas, é que a nova visão adotada pelos proprietários rurais voltados a empreendimentos, no mercado e na rentabilidade, adquiridas com nova estrutura transformada em empreendimento rural, melhorou muito a qualidade do trabalho desenvolvido em áreas rurais, e tornou-se indispensável a discussão permanente de como, onde e quando será desenvolvido, para quem será oferecido, sendo indispensável o uso contínuo de gestão e planejamento em tais propriedades, que constem desde os objetivos, as estratégias e metas alcançadas a partir da criação de etapas para gerir melhor as áreas e portanto nortear todo o trabalho administrativo do proprietário rural, na busca da obtenção de lucros.

Palavras-chave: Agronegócio. Gestão Rural. Administração Rural. Gerenciamento rural. 


\begin{abstract}
The present work discussed bibliographically the practices of management of the rural properties, focus of study, the execution through the administration in these properties facilitating for the rural producers in the decision making for agricultural properties, in order to obtain better economic results and consequently increase of the profits. The general objective was to expose administrative systems that cooperate to significantly improve rural management within agricultural properties. And the specific objectives are an explanation of the power that agribusiness is in the country, identifying the models of Rural Management with success in their administrations and describing the steps to be followed within Rural Management.

Regarding the research classifications, the approach classified as hypothetical-deductive was applied, as for the objectives it was considered exploratory and explanatory, as for the procedures it was classified as descriptive bibliography and, finally, data collection was performed through indirect documentation. The results obtained confirmed the importance of administration in the management of rural properties. Thus, it was concluded that, in line with what could be noted during the research, the new vision adopted by rural owners focused on enterprises, on the market and on profitability, acquired with a new structure transformed into a rural enterprise, greatly improved the quality of the work developed in rural areas, and it has become indispensable the permanent discussion of how, where and when it will be developed, for whom it will be offered, being essential the continuous use of management and planning in such properties, which are included from the objectives, the strategies and goals achieved from the creation of steps to better manage the areas and therefore guide all the administrative work of the rural owner, in the pursuit of obtaining profits.
\end{abstract}

Keywords: Agribusiness. Rural Management. Rural Administration. Rural Direction. 


\section{LISTA DE SIGLAS E REDUÇÕES}

ABAG - Associação Brasileira do Agronegócio

PIB - Produto Interno Bruto

CNA - Confederação Nacional da Agricultura

EUA - Estados Unidos da América

ERP - Enterprise Resource Planning

TI - Tecnologia da Informação

ABMR - Associação Brasileira de Marketing Rural

ABRMA - Associação Brasileira de Marketing Rural e Agronegócio

FAO - Food and Agriculture Organization

OCDE - Organização para a Cooperação e Desenvolvimento Econômico 


\section{LISTA DE FIGURAS}

Figura 1 - Elementos do sistema de agronegócio............................................................17

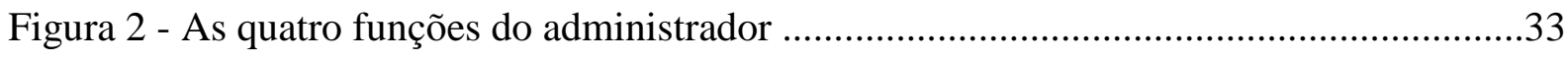

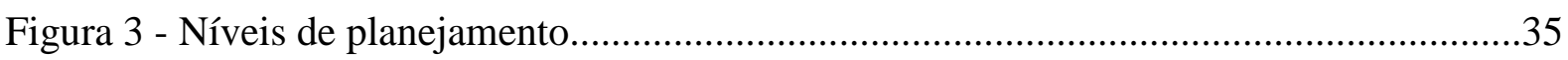




\section{LISTA DE QUADRO}

Quadro 1 - Aspectos relevantes dos autores citados... 


\section{SUMÁRIO}

1. INTRODUÇÃO....................................................................................................

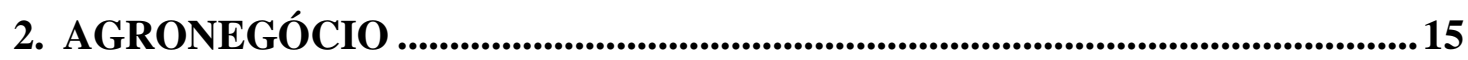

2.1 Perspectivas Para o Agronegócio Brasileiro...........................................................18

2.2 Importância Econômico-Social do Agronegócio Brasileiro ....................................... 19

3. GESTÃO RURAL.........................................................................................................21

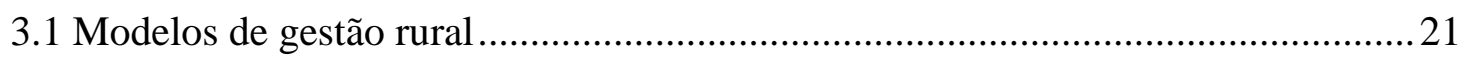

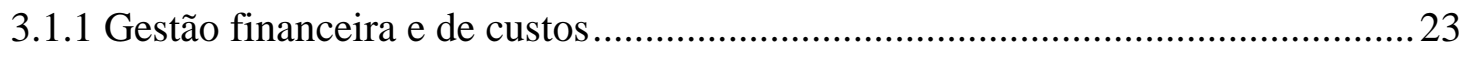

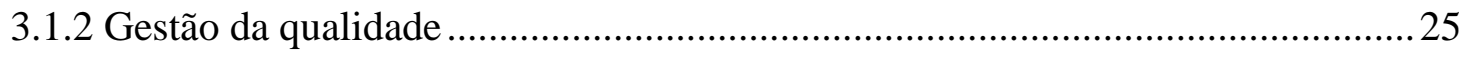

3.1.3 Gestão de processos e da tecnologia da informação..............................................2 26

3.1.4 Gestão do Marketing Agrícola ou Rural ...............................................................2 28

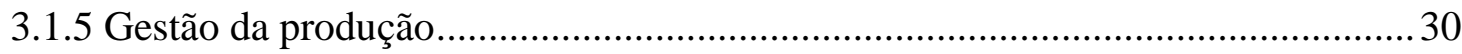

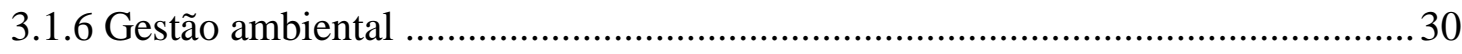

3.2 Etapas da Gestão Rural ........................................................................................ 32

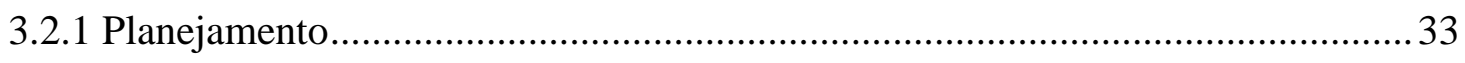

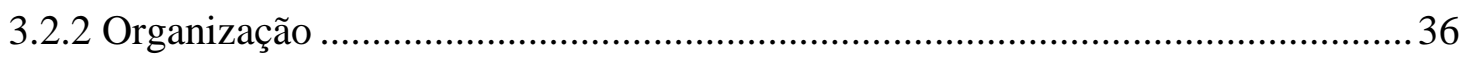

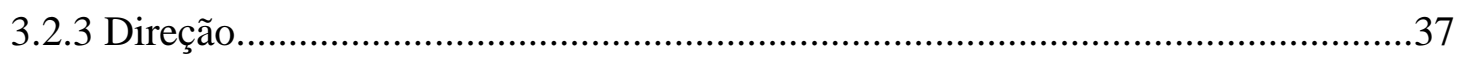

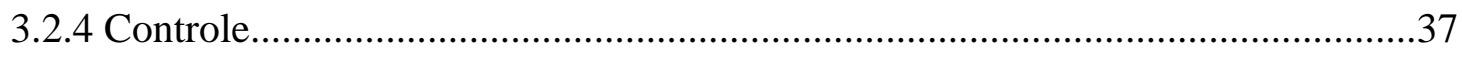

4. ASPECTOS RELEVANTES DOS AUTORES CITADOS..................................39

5. METODOLOGIA ...............................................................................................................4

6. RESULTADOS E DISCUSSÕES .........................................................................43

7. CONSIDERAÇÕES FINAIS.................................................................................45

REFERÊNCIAS........................................................................................................46 



\section{INTRODUÇÃO}

O produtor rural, atualmente, já não se limita a apenas manter o foco em sua produção, ele está sentindo dia após dia a necessidade de desvendar o meio em que trabalha, ter conhecimento para gerenciar sua empresa rural, seja ela de grande ou pequeno porte, e implantar novas tecnologias que o auxiliem nas etapas a serem desenvolvidas. O conhecimento do que é a gestão rural é fundamental para desenvolver essa nova fase, e compreender que na gestão rural deve-se ter um sistema de gestão que disponibilize treinamentos e progressos para uma excelente procura de resultados que atendam ao grupo em geral. Ainda possui uma insuficiência na estrutura da administração rural quanto ao gerenciamento das propriedades rurais onde se procura muito a competência técnico-teórica, mas se omite da capacidade que os administradores podem gerar dentro de uma propriedade rural.

Com a ideia centralizada de que atualmente já não é mais uma curiosidade dos produtores rurais conhecerem a gestão rural, e sim uma necessidade, levanta-se o seguinte problema: o que fazer para melhorar o desenvolvimento da gestão rural na parte da agricultura nas propriedades rurais?

Batalha (2007, s.p.) considera que a administração abrange várias áreas de suma importância para as organizações, sendo que uma das áreas é a gestão rural, que é indispensável ao cotidiano das propriedades rurais, nas quais o trabalho será realizado. O interesse nesta área se dá pelo fato de a área rural ser muito carente em informações para seus gestores, e essa desinformação veio então a despertar o interesse na área, para assim haver um conhecimento aprofundado de como é realizada a gestão rural, e a real importância da administração na área rural. Percebe-se que a grande maioria das propriedades não possui um sistema de gestão no cotidiano, e isso pode refletir diretamente nos negócios. E como a maioria das propriedades não têm nenhum tipo de sistema para o seu gerenciamento, esse trabalho traz muito interesse ao produtor, pois, sabendo como gerenciar e obter resultados para o seu negócio, e ao mesmo tempo, despertando a importância de um sistema de gestão para a sua propriedade, consequentemente, melhorando o gerenciamento do negócio.

Desta forma, o presente trabalho teve como objetivo geral expor sistemas administrativos que cooperam para a melhoria significativa da gestão rural dentro das propriedades agrícolas. E como objetivos específicos explanou a potência que é o agronegócio no país, identificou os modelos de Gestão Rural com êxito em suas administrações e descreveu as etapas a serem seguidas dentro da Gestão Rural. 
A proposta deste estudo fundamenta-se na necessidade de se discutir mecanismos e práticas de gestão rural que sejam mais eficientes e complacentes com a realidade social e econômica da agricultura no Brasil. É notório e consensual da classe dos produtores agrícolas que a busca por mecanismos mais eficientes pode vir a melhorar as etapas produtivas condicionantes para a geração de renda. Posto isso, de acordo com Amaral e Dantas (2010), a agricultura aumentou cada vez mais a produção devido aos avanços tecnológicos, por outro lado, o mercado é instável e competitivo. Por isso, se faz necessária a busca por ferramentas e tecnologias para aperfeiçoar a produção, e isso pode ser alcançado por meio da implementação de medidas de gerenciamento apropriadas ao ambiente de produção em questão. $O$ gerenciamento eficaz dos recursos físicos e financeiros vem a ser uma condição para sobrevivência e sucesso de todo produtor rural, porque é possível ajuda-lo a tomar decisões para sua propriedade. Da maneira que, a justificativa cultural se torna perceptível que toda organização agrícola, ou seja, os produtores rurais têm seus comportamentos e crenças para trabalhar e incentivar os seus funcionários, cada um com sua cultura individual, e em busca de resultados assertivos.

A metodologia utilizada foi definida por processo de uma meticulosa pesquisa bibliográfica descritiva, sendo assim, as informações contidas constam em artigos científicos, sites e livros que têm a intenção de proporcionar conhecimento e esclarecimento sobre a temática estudada. Envolve também a finalidade aplicada, a pesquisa utilizada é qualitativa, os objetivos se enquadram entre exploratórios e explicativos e o método de abordagem é apresentado como hipotético-dedutivo.

O trabalho de conclusão de curso se estrutura em sete capítulos, nesta conformidade, o primeiro aborda sobre a introdução, o segundo trata de assuntos sobre o agronegócio, o terceiro sobre a gestão rural, os modelos de gestão rural e as etapas da gestão rural, o quarto capítulo aborda os aspectos relevantes dos autores citados, o quinto capítulo é formado pela metodologia que foi utilizada para preparação da análise afim de alcançar resultados, o sexto capítulo que trata dos resultados e discussões e finalmente o desfecho se dá com as considerações finais reforçando as partes mais importantes. 


\section{AGRONEGÓCIO}

Agronegócio é uma expressão traduzida do inglês e tem origem na palavra “agribusiness", sendo assim, se refere a negócios no setor agropecuário. Inclui todos os processos desde a fabricação básica dos insumos, produção agrícola, os processos relacionados a produção, chegando até o consumidor final, onde deve oferecer qualidade e satisfação ao consumidor. (BIALOSKORSKI NETO, 1994).

Para Callado (2006), o agronegócio é a soma das organizações que produzem matérias-primas agrícolas, ou seja, as propriedades rurais, as organizações de processamento e suprimento. Com base nesta visão, o agronegócio pode ser descrito como qualquer relação comercial envolvendo produtos agrícolas.

O agronegócio é um conceito iniciado na década de 1980. Para alguns autores, é uma ideologia transformacional que constrói um sistema capitalista de proprietários de terras agrícolas. No Brasil, o conceito de latifúndio trouxe imagens de exploração, escravidão e trabalho manual, terras extremamente concentradas, atraso político e econômico. Portanto, este é um espaço que pode ser ocupado e proporciona o desenvolvimento nacional usando tecnologia e sustentabilidade (FERNANDES, 2005).

O agronegócio brasileiro teve um grande salto nas décadas de 70 e 90 do século 20, com o avanço da Tecnologia e da Ciência, o que veio a proporcionar o controle de regiões que antes eram consideradas inábeis para o cultivo agrícola. Com isso houve o surgimento da oferta de um vasto número de produtos. O Brasil se tornou, então, aquele que conseguiu dominar a agricultura tropical, atraindo a atenção de todos os nossos adversários e parceiros mundialmente. O crescimento do Grupo do Complexo do Agronegócio comprova que, quando os setores de armazenagem, processamento e distribuição final são os transportadores que maximizam o valor dos produtos vendidos aos consumidores e o valor integrado aos produtos agrícolas, a cadeia do agronegócio aumenta o valor das matérias primas agrícolas consolidando uma forte rede de inter-relação entre a agricultura e a indústria. (LOURENÇO; DE LIMA, 2009).

O agronegócio é agora considerado como um sistema vinculado, cobrindo pesquisa, investimento, tecnologia de produção, transporte, processamento, distribuição e preço. Por meio do relacionamento interdepartamental entre as unidades de produção agrícola a montante e a jusante, é formado o sistema do agribusiness ou agronegócio. (ARAÚJO, 2005). 
Araújo (2003) enfatiza que o agronegócio pode ser visto como um sistema agroindustrial, composto por várias etapas da cadeia de produção agrícola em sequência e sinergicamente, uma fornecendo a outra, tornando todos os participantes mais competitivos em seus mercados altamente competitivos.

Nesse sentido, o autor aumenta a importância de obter uma visão sistêmica do agronegócio com o entendimento do agronegócio, os vários componentes e as inter-relações do agronegócio, pois são uma ferramenta indispensável para todos os tomadores de decisão, sejam autoridades públicas ou agentes econômicos privados, para formular políticas estratégicas com maior previsão e eficiência máxima. (ARAÚJO, 2003).

Segundo Batalha (2001), agronegócio é a soma de negociações relacionadas a agricultura segundo a perspectiva econômica.

Na visão de Batalha (2001), o agronegócio é uma série de fatores que geram riquezas retiradas de recursos naturais e renováveis, divididos em três etapas:

I. "Antes da Porteira" que inclui toda a cadeia de desenvolvimento, serviços, pesquisa e o fornecimento de insumos fundamentais para a produção agrícola comercial;

II. "Dentro da porteira”, onde está a imagem do empreendedor rural ou como é conhecido, o produtor agrário, responsável por agregar valor econômico significativo, dado que o país atualmente é um forte exportador de commodities, originário do trabalho desse empreendedor rural;

III. "Depois da Porteira", que se representa pela indústria agrícola, agentes de comercialização, distribuidores e o comercio em geral.

Mendes e Padilha (2007, p. 45) falam sobre outro conceito de agronegócio: o volume operacional total de produção e distribuição de produtos agrícolas. Isso inclui todas as finanças, classificação, transporte, marketing, bolsas de mercadorias, seguros, entre outros. A medida em que a agricultura se modernizou e começou a aumentar os serviços fora da porteira produtiva, todos esses negócios se tornaram cada vez mais complexos.

A figura 1 mostra que o agronegócio excede os limites da "propriedade rural ou fazenda" (agricultura ou pecuária) e envolve todas as pessoas que estão direta ou indiretamente envolvidas no fornecimento de alimentos aos consumidores. Em outras palavras, o agronegócio não é adequado apenas para pessoas que trabalham na terra, mas também para empresas que participam do fornecimento de insumos ou serviços nessa cadeia, de modo direto ou indireto. 
Figura 1- Elementos do sistema de agronegócio

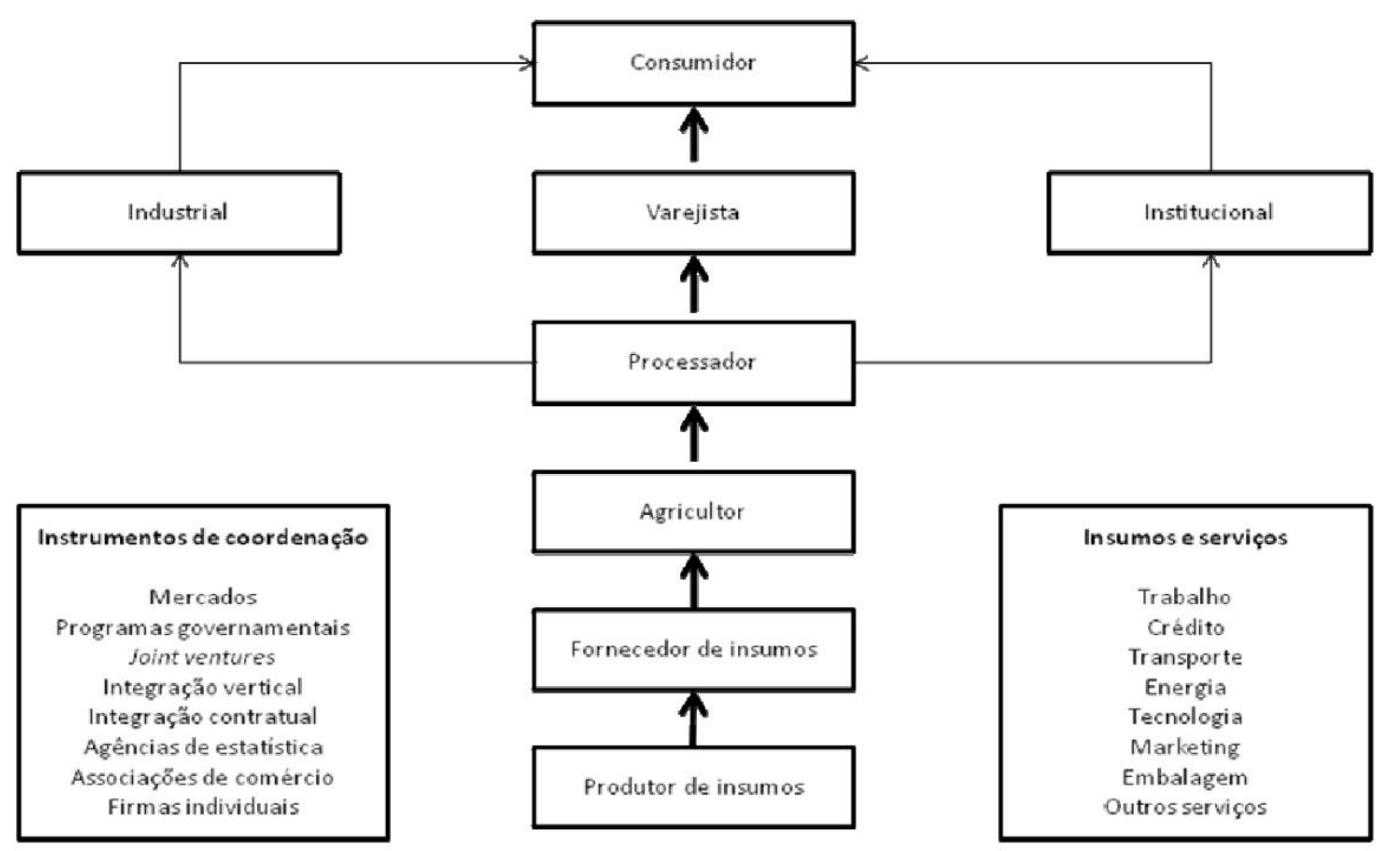

Fonte: Mendes e Padilha (2007).

Figura 1 - Elementos do sistema do agronegócio. Fonte: Mendes e Padilha (2007).

A seguir pôde constatar de modo sintético o conceito de agronegócio, encaminhando junto totalmente a complexidade a que ele está exibido.

Agronegócio é a soma das operações de produção e distribuição de suprimentos agrícolas, das operações de produção nas unidades agrícolas, do armazenamento, processamento e comercialização dos produtos agrícolas e itens produzidos a partir deles. E envolve desde a pesquisa científica até a comercialização de alimentos, fibras e energia (ASSOCIAÇÃO BRASILEIRA DO AGRONEGÓCIO - ABAG, 2019).

Segundo a Associação Brasileira do Agronegócio - ABAG (2009) teve-se ainda a explicação a seguir.

O termo 'agribusiness' surgiu na Universidade de Harvard, EUA, em 1957. Os pesquisadores John Davis e Ray Goldberg atribuíram ao "business" o sentido de 'ocupação' e não de 'negócio' propriamente dito. Para o português o termo foi traduzido de diversas formas, mas a palavra agronegócio acabou sendo uma das mais utilizadas. (ASSOCIAÇÃO BRASILEIRA DO AGRONEGÓCIO - ABAG, 2009). 
Deste modo, o termo agronegócio trouxe a noção de cadeia produtiva com suas junções entrelaçadas e sua interdependência, e ainda buscou envolver todos as ligações intersetoriais dos setores agrícolas.

\subsection{Perspectivas Para o Agronegócio Brasileiro}

Para Contini (2001, s.p.), as perspectivas são promissoras. O Brasil possui terras ricas, planas e baratas, além do cerrado com 80 milhões de hectares de terra, dispondo de produtores rurais que podem converter esses potenciais em produtos comercializáveis e possuem conhecimento e tecnologia agrícola que podem transformar recursos em produtos. De qualquer ponto de vista da análise de mercado, a escala da aquisição do Brasil no campo do agronegócio é impressionante.

Devido às condições extremamente convenientes para o mercado que se mantém em plena expansão, com enorme espaço territorial, mão-de-obra disponível e diversas questões relacionadas à situação internacional, o país é considerado por vários especialistas como o principal candidato ao status de fornecedor global de alimentos em âmbito universal.

Para Nogueira (2016), é esperado que nos próximos dez anos com base no aumento da produtividade e no aumento da área agrícola, que o segmento das culturas do Brasil mais utilizadas continue a crescer. Após o ajuste pela inflação, espera-se que os custos do produtor sejam relativamente estáveis.

Mesmo que a cadeia do agronegócio, ou seja, antes, durante e depois da porteira do Brasil, enfrente problemas de expansão e desenvolvimento, ainda assim, é necessário mostrar que quaisquer atividades associadas ao agronegócio no Brasil progredirão para garantir a estabilidade das contas públicas, internas e externas. Além das conquistas econômicas e sociais, esses desafios também devem ser superados: criar muitos empregos nas áreas urbanas e rurais, melhorar a segurança alimentar, criar dinheiro para o país, expandir a renda dos produtores agrícolas e consolidar os trabalhadores nas áreas rurais (BATALHA, 2009, p. 14)

Até 2015, a participação de países no mercado internacional de soja poderá aumentar dos atuais $36 \%$ para $46 \%$. Se avaliarmos a produção de frango, o salto aumentará de $58 \%$ para $66 \%$. Nas regiões onde a participação do país no comércio mundial ainda é pequena, espera-se que o desenvolvimento seja ainda maior. Por exemplo, de acordo com as previsões de especialistas da região, a participação do Brasil em fazendas de suínos deve ser quadruplicada e ocupar metade do mercado internacional. "Num futuro próximo, a suinocultura 
será tão importante para a balança comercial do país quanto são hoje o frango e a carne bovina" (NETO, 2007 apud SEIBEL, 2007, s.p.).

O agronegócio é o maior negócio do mundo e brasileiro. No mundo, corresponde a geração de 6,5 trilhões de dólares por ano e, no Brasil, é de cerca de R \$ 350 bilhões, representando 26\% do PIB (29\%, segundo a Confederação Nacional da Agricultura - CNA). A maioria deste montante faz referência a negócios externos, os negócios fora da porteira, o que envolve o suprimento de insumos, o beneficiamento/processamento das matérias-primas e a distribuição dos produtos. (STEFANELO, 2002, s.p.).

Segundo Nogueira (2016), espera-se que a soja continue sendo o produto agrícola mais importante do Brasil. Atualmente, o país é o segundo maior produtor depois dos Estados Unidos, mas espera-se que essa diferença diminua devido ao crescimento contínuo da produção brasileira de soja durante o período previsto. Entre os principais produtores e exportadores de oleaginosas, o Brasil tem o maior potencial de expansão da produção. Atualmente, a produtividade do país é semelhante à dos Estados Unidos, mas há uma grande quantidade de terra disponível para expandir a produção de soja. Os Estados Unidos são concorrentes fortes na produção de milho, o que faz com que seu potencial de modificar grandes áreas da produção de soja e cumprir a demanda futura de oleaginosas seja limitado.

Segundo Datum (2014), a união da tecnologia e vários setores envoltos na agricultura brasileira está caminhando para um relacionamento mais próximo, buscando maior produtividade. A corporação afirmou que essa combinação merece a atenção das empresas de tecnologia da informação, que produzirão confiabilidade na implementação de projetos que visam melhorar os sistemas de produção agrícola. Com assistência tecnológica e desenvolvimento econômico constante, a produção agrícola se tornará ágil e viável.

Essas foram partes que fortalecem como é importante o agronegócio no Brasil, e de sua enorme competitividade, aplicação de alta tecnologia e geração de empregos e riquezas para o território nacional.

\subsection{Importância Econômico-Social do Agronegócio Brasileiro}

O agronegócio é de suma importância na geração de renda e para a economia geral do país. No plano social, a agricultura é o setor econômico que responde pelo maior consumo de mão de obra, empregando aproximadamente 17 milhões de pessoas. Se contabilizarmos os outros 10 milhões de componentes a que se refere o agronegócio, isto representará um total de 27 milhões de pessoas. O valor da mão de obra neste setor é superior ao valor da produção: em 
1995, para cada 1 milhão de reais, 182 pessoas estavam empregadas na agricultura, 25 na extração mineral e 38 na construção civil (CONTINI, 2001, s.p.).

Todas as atividades referentes ao agronegócio envolvem mais de 1/3 do PIB do Brasil. Mesmo reconhecendo os benefícios de transformar a população agrícola em uma sociedade urbana industrial, não se deve esquecer sua capacidade limitada de absorver trabalho. Especialmente em áreas subdesenvolvidas, a agricultura, a agroindustrialização e áreas afins serão cruciais para o crescimento da renda e do emprego (RENAI, 2007, s.p.).

De acordo com Miceli (2008, pág.40): O agronegócio, igualmente a qualquer outra atividade produtiva, depende do lucro obtido na produção. Com isso, presume-se que os empenhos para conseguir uma melhor eficácia dos fatores de produção precisam ser buscados incansavelmente, ao passo que as reduções nos custos de produção necessitam de inúmeros fatores que, por sua vez, não são controlados pelo gestor do agronegócio.

As pestes, doenças e os fatores climáticos que destroem a lavoura são exemplos que influenciam na oferta e demanda dos produtos e, com isso, constituem-se de variantes que podem explicar os investimentos das commodities (MICELI,2008, pág. 43).

Há uma questão de bastante importância a ser analisada na produção de alimentos no mundo que é a taxa decadente do crescimento da produção agropecuária agregada (cereais, frutas, vegetais e hortaliças, raízes e tubérculos, carnes e leite), pois o crescimento da produção mundial de alimentos diminuiu nos últimos anos. Com isso, espera-se que no estágio atual de 2015, o índice caia para menos de $2 \%$ ao ano e permaneça abaixo de 1,5 entre 2015 e 2030 (MENDES, 2007, pág.141).

Os preços reais dos produtos são planejados para readquirir o declínio a longo prazo de acordo com a tendência do crescimento da produtividade e na baixa dos preços. Entretanto, o Brasil está preparado] para se tornar um grande fornecedor de produtos agrícolas que possa atender à crescente demanda mundial, iniciada na Ásia. (OCDE-FAO, 2015).

Por conseguinte, através da recente crise de câmbio, o agronegócio tem sido um fator que encolheu as discrepâncias nas contas externas do Brasil. A agricultura colaborou decididamente para as exportações com o valor comercial setorial positivo. 


\section{GESTÃO RURAL}

Segundo Breitenbach (2014), a Gestão Rural é a operação que visa obter resultados com o uso consciente em uma propriedade rural, com a finalidade de ser sustentável buscando sempre a produção.

Para Hoffmann (1987), a Gestão Rural é a ciência administrativa introduzida em áreas como recursos humanos, marketing, finanças e comércio, que são tão prioritárias quanto a parte de produção.

Segundo Marion (2007), uma empresa rural caracteriza-se por cultivar a terra através do solo, transformação de produtos agrícolas e criação de animais.

De acordo com Hoffmann (1987, s.p.) a "Administração Rural é o estudo que considera a organização e operação agrícola, visando ao uso mais eficiente dos recursos para obter resultados compensadores contínuos".

Para Silva (2013, p.29) “[...] a Administração Rural preocupa-se primeiramente com o problema de conseguir a combinação mais lucrativa dos diversos fatores envolvidos na produção".

A Administração Rural abrange uma série de atividades que favorece os produtores rurais à tomada de decisões, para obterem melhores resultados econômicos, conservando a produtividade da terra. Diante da nova ordem mundial, a globalização, ela passa por várias situações estruturais e comportamentais, usando conceitos antigos e reconhecendo suas teorias para buscar melhorias organizacionais para empresas rurais (SILVA, 2009).

Neste sentido, a Administração Rural é vital para ajudar o gestor rural a tomar medidas que podem encaminhar e orientar as próximas decisões. Portanto, a estratégia adotada é diversificar a produção, de acordo com a disposição de recursos, com o a intenção de garantir o autoconsumo e obter maior renda. (LIMA et al., 2005).

\subsection{Modelos de gestão rural}

Para Pereira e Santos (2001, p.47), o modelo de gestão “ é compreendido como o conjunto de princípios, técnicas e explicações que orientam a concepção e o modo de funcionamento de todos os elementos constituintes de uma organização."

Lourenzani e Souza Filho (2009, s.p.) lidam com o processo de gestão das propriedades rurais comparando esse processo ao de empresas sistêmicas, onde as propriedades enfrentam a influência dos ambientes externo tais como o clima, preço dos produtos, políticas 
agrícolas, etc; e interno, onde mencionam os recursos humanos, planejamento da produção etc. Para eles, é baseando- se nessas forças que as tomadas de decisões veem resultar ao que conhecemos como gerenciamento, que é essencial para a realização do desenvolvimento da propriedade.

De acordo com Bateman e Snell (1998, s.p.), a gestão de uma empresa é um processo para alcançar objetivos organizacionais por meio da cooperação de pessoas e recursos. As principais funções que desempenham são planejamento, implementação e controle de atividades. A função do planejamento é especificar o objetivo a ser alcançado e determinar as medidas apropriadas para alcançar as metas designadas. A implementação envolve a execução de ações previamente identificadas e planejadas, coordenando os recursos disponíveis. Finalmente, a função de controle visa garantir que os objetivos planejados sejam alcançados monitorando as atividades e adotando ações corretivas quando necessário.

Segundo Santos e Marion (1996), os fatores que abalam os desempenhos econômicos da empresa agrícola podem ser externos ou internos. Os gestores não podem controlar os fatores externos, como preços de produtos, políticas agrícolas e clima. Mesmo assim, é necessário entendê-las para tomar decisões adequadas a condições favoráveis ou desfavoráveis. Os fatores internos, como os relacionados aos recursos humanos, ao planejamento da produção, recursos financeiros e planejamento de marketing, são bem controlados pelo gestor por intermédio de procedimentos de gerenciamento. Quanto maior for o entendimento sobre a estrutura e seu funcionamento operacional juntamente aos fatores de produção, melhores serão as chances de tornar favoráveis os resultados econômicos.

Neste caso, pode-se dizer que a gestão de empresas rurais é um procedimento de tomada de decisão que faz a avaliação da alocação de recursos limitados entre várias possibilidades de produção em um ambiente onde o setor agrícola apresenta características de risco e incertezas. Apesar do seu tamanho, o gerenciamento da propriedade rural foi um dos fatores essenciais para atingir o desenvolvimento sustentável total da propriedade.

Para isso, Santos e Marion (1996, p. 16), definem que a missão do administrador rural é planejar, controlar, decidir e avaliar os resultados, cujo objetivo é maximizar os lucros, a motivação permanente, o bem-estar social dos funcionários e a satisfação do cliente e da comunidade.

Segundo Procópio (1997), o gerenciamento de atividades agrícolas requer informações sobre quantidades físicas e resultados financeiros, mas muitas das informações necessárias para que haja um gerenciamento adequado são registradas apenas na memória daqueles que o fazem por notas informais. 
Conforme Zanchet \& Francischetti Junior (2006, p. 9), o produtor precisa de muita informação, e necessita cruzar e analisar essas informações para formar uma estrutura que permita a tomada de decisões. Um bom gerenciamento da propriedade constata os aspectos ineficazes da atividade e, ao mesmo tempo, fornece condições suficientes para corrigir esses problemas.

Crepaldi (2012) acredita que um sistema administrativo rural moderno é uma maneira de os agricultores gerenciarem suas propriedades determinando metas a serem alcançadas. Ao fornecer planejamento, controle e tomada de decisão, resultados como rendas adicionais, diluição de custos e economia de insumos podem ser obtidos, ou seja, a propriedade rural se tornará um modelo para práticas de gerenciamento interno bem-sucedidas.

Crepaldi (2012, p.40) propôs um método de melhoria para o planejamento agrícola, aonde primeiro é preciso analisar a propriedade, para depois adotar medidas de mudanças e traçar novas estratégicas. Os primeiros passos a seguir, abordam os seguintes itens:

I. Características gerais da organização: estrutura jurídica acionária; influências;

II. Objetivos e estratégia: metodologia de definição dos objetivos; estratégias adotadas e investimentos realizados;

III. Finanças: administração financeira; balanços e contas de resultados; fontes e aplicações de recursos; planejamento e previsão financeira;

IV. Sistemas administrativos e práticas adotadas: estrutura organizacional; processo de tomada de decisão; comunicação; sistema interno de informações; planejamento e controle; técnicas empregadas; cultura organizacional;

V. Recursos humanos: administração de pessoal; quadro de pessoal; remuneração e motivação;

VI. Conclusões sobre o estado atual da administração.

Portanto, é responsabilidade do administrador rural encontrar soluções para responder as perguntas fundamentais do seu empreendimento para que obtenha resultados positivos no momento do planejamento estratégico para sua propriedade.

\subsubsection{Gestão financeira e de custos}

De acordo com Oliveira, Perez Jr., Silva (2005, s.p.), a palavra Gestão deriva do latim gestione que significa gerir, gerência, administração. Administrar refere-se a fazer o planejamento, a organização, a direção e o controle de recursos, para atingir um determinado 
objetivo. Gerenciar significa fazer as coisas acontecerem e guiar a organização em direção a seus objetivos. Por isso, Gestão é o processo de conduzir para a conquista dos resultados desejados.

Como a maioria das decisões é avaliada em termos financeiros, o empresário rural deve exercer o papel de administrador financeiro de seu empreendimento. As finanças proporcionam um mapa com números e análises que auxiliam no planejamento, na solução de problemas e nas tomadas de decisões. Portanto, o controle dos resultados deve autorizar o reconhecimento dos problemas operacionais e avaliação de desempenho de cada unidade estratégica de produção (CREPALDI, 1998).

Barros, Monteiro e Prado (2011) enfatizam a importância de tratar a propriedade rural como um negócio que deve ter como objetivo gerar renda. Portanto, o empreendedor rural deve buscar a viabilidade econômica da empresa, e saber que ele só alcançará esse objetivo mediante uma gestão de qualidade, que exija metas claras, investimento tecnológico e controle das informações.

Martins (2003, s.p.), fala que o custo também é um tipo de gasto, só que reconhecido por essa razão, isto é, como custo, ao se utilizar de fatores de produção (bens e serviços), para a produção de produtos específicos ou a prestação de serviço.

Brum (2005) defende o uso de excelentes práticas de gestão pelos empreendedores rurais para obterem melhoria na contabilização dos custos, porque é importante que os produtores saibam como calcular seus consumos reais de produção e não acreditem apenas em informações sobre custos agrícolas divulgados pelo mercado.

Lourenzani e Souza Filho (2009, p.77) disseram que para encarar os atuais desafios colocados pelo mercado, os produtores rurais precisam adotar sistemas que possam calcular os custos e possibilitar a tomada de decisões de forma eficiente e segura.

O objetivo de gerenciar os recursos financeiros e orçamentários das instituições rurais é avaliar a viabilidade de investimentos produtivos em face dos recursos disponíveis. É necessário identificar, analisar e interpretar as informações sobre as receitas e despesas da empresa para escolher entre alternativas de produção mais viáveis. (LOURENZANI; SOUZA FILHO, 2009, p. 77).

Por esse motivo, é necessário registrar sistematicamente as informações contábeis e não contábeis da organização. Obviamente, o grau de elegância e complexidade desses registros deve ter compatibilidade com o tamanho e o nível de desenvolvimento da organização. Assim sendo, mesmo pequenas empresas, com poucos recursos, devem recolher as informações sobre suas receitas e despesas. Mesmo que em forma de registro manual, pois tais registros 
contribuirão para decisões mais uniformes em comparação com decisões tomadas de forma intuitiva. (LOURENZANI; SOUZA FILHO, 2009).

O objetivo da contabilidade de custos segundo Martins (2010), é controlar os custos para gerar dados que venham a definir padrões e orçamentos, analisar mudanças, tentar reduzir os custos e auxiliar na tomada de decisões.

A contabilidade de custos tem vários propósitos para os agricultores e empresas rurais. O objetivo geral é usar as informações obtidas para melhor gerenciar e controlar. Segundo Callado e Callado (2009) o produtor pode usar essas informações para seleções de práticas agrícolas em outros períodos, assim como o governo e entidades de classe podem usar essas informações para políticas públicas, de modo a proporcionar competitividade entre os produtos vendidos.

Para Marion (2007), nas áreas rurais, os métodos de gerenciamento da contabilidade de custos são cada vez mais necessários.

Neste aspecto, o que foi evidenciado é o atendimento das precisões de cada propriedade rural, sendo importante que elas tenham um entendimento das informações a elas necessárias, para que não ocorra exageros de dados e afete o propósito intencionado.

\subsubsection{Gestão da qualidade}

De acordo com Falconi (1992, s.p.), o gerenciamento da qualidade é um tipo de gerenciamento que se concentra na qualidade da produção e dos serviços de uma empresa específica.

Segundo Falconi (1992, s.p.), o verdadeiro padrão de boa qualidade é a preferência do consumidor. Isso garantirá a sobrevivência da sua empresa hoje e no futuro pois os consumidores preferirão seus produtos aos de seus concorrentes.

Pode-se inferir que a qualidade do produto se define como um atributo que combina várias características que determinam a satisfação do cliente. Portanto, em termos de produtos agrícolas, a qualidade pode ser vista como a combinação de características e condições subjetivas (como sabor, aparência, embalagem, higiene, textura, composição, valor nutricional, beleza, estética, marca, etc.) (TOLEDO 2001 apud LOURENZANI; SOUZA FILHO, 2009).

Os autores também destacam que garantir a qualidade dos produtos se refere a desenvolver mecanismos internos de particularidades, como rotinas, comportamentos e ideias, visando obter produtos com características e especificidades mínimas. 
Consequentemente, devem ser adotados os princípios de higiene e limpeza, organização e boas práticas de produção.

$\mathrm{Na}$ produção agropecuária, os seguintes fatores foram determinantes para o desenvolvimento de sistemas de gestão da qualidade: o atendimento à necessidade dos clientes, os requisitos de qualidade impostos pelo mercado, a legislação vigente e as exigências de certificação. “A implementação desses sistemas é pré-condição para a rastreabilidade dos produtos, a segurança do alimento e do produto e, a certificação de origem e qualidade". (LOURENZANI; SOUZA FILHO, 2009, p. 79).

De acordo com JURAN (1991), a qualidade é as características do produto que atende às necessidades do cliente $\mathrm{e}$, portanto, podem proporcionar a satisfação pelo produto. A qualidade é falta de defeitos.

A qualidade do produto é definida por TEBOUL (1991), como a capacidade de atender à demanda com o melhor custo possível durante a compra e o uso, minimizando as perdas e sendo melhor que os concorrentes.

Kano citado por MERLI (1993) propõe os conceitos de "qualidade positiva" e "qualidade negativa". A "qualidade positiva" diz respeito a um nível que excede as necessidades e expectativas do consumidor, proporcionando maior satisfação. Quanto mais excede as expectativas, maior será a sua satisfação. A “qualidade negativa” indica o nível de produtos não qualificados, causando a insatisfação do cliente, mas se o problema tiver sido eliminado, não produzirá resultados satisfatórios.

Desse modo, enfrentou-se tais complexidades de funções simultâneas requerendo competências gerenciais, inexistentes na maior parte dos produtores rurais e em seus negócios, causada pela ausência de uma visão sistêmica da organização rural.

\subsubsection{Gestão de processos e da tecnologia da informação}

Desde o desenvolvimento do computador eletrônico, na década de 1950, até o boom da internet, na década de 90, a sociedade testemunhou a automação dos processos de produção e a informatização do trabalho de escritório. A gestão atualmente é alcançada por meio de sistemas de informação que contém regras de negócio e definem quão competitivo uma empresa ou setor será (LAURINDO; ROTONDARO, 2011).

Batalha (2001) enfatiza que a implementação dos sistemas de gerenciamento corporativos ou Enterprise Resource Planning (ERP) foi mesclada e se tornou crucial em vários 
campos econômicos. Em alguns casos, estabeleceu-se como parte indispensável da gestão de negócios em vários campos econômicos.

Goleman et al. (2009) acreditam que os gestores têm que avaliar o impacto da internet nos negócios e desenvolver estratégias para integrar seus processos nos mundos físico e virtual.

Os componentes tecnológicos da internet podem ajudar as organizações a desenvolver processos a serem projetados, planejados, executados ou desenvolver juntos em três áreas. Deming (1982) disse que tudo que as empresas praticam é feito através de processos. No entanto, se a definição não estiver clara, as empresas podem perder tempo, dinheiro e posição no mercado.

Processo é conceituado por Davenport (1994, p. 23), como um conjunto de atividades e métricas estruturadas projetadas para produzir produtos para clientes ou mercados específicos. Contém uma ordem própria de atividades de trabalho no tempo e no espaço, com início, fim e entradas e saídas claramente definidas: uma estrutura de ação.

Para uma organização, o uso de processos pode melhorar a qualidade e a velocidade da tomada de decisão, reduzir os riscos de mercado e desenvolver estratégias de defesa contra os concorrentes, ao mesmo tempo em que também novas estratégias são desenvolvidas para buscar e captar novos clientes (MATTAR, 2007).

Para esse autor, o processo acontece conforme são aplicadas ferramentas que ajudam as empresas a desenrolar suas atividades, que as fazem fluir, como os processos de negócio, organizacionais e gerenciais.

Segundo Goleman et al. (2009), os processos de negócio envolvem a fabricação de produtos ou prestação de serviço; os processos organizacionais correspondem as funções da organização e seus subsistemas; os processos de trabalham com a gerência e à supervisão da organização para orientar novas ações, monitora e apoiar novas decisões.

Para Tanenbaum (2003), o processo é de forma básica um sistema em execução. Ainda que não seja um sistema técnico, mostra uma maneira de estruturar atividades e tarefas para que a empresa não se afaste de suas atividades.

Velloso (2004) diz que a Tecnologia da Informação também deve ser usada onde os processos são bem projetados definidos. Ele alerta que seja pela internet ou por outras tecnologias, o desenvolvimento e o gerenciamento de negócios sempre dependem da conectividade. 
Tecnologia da Informação é o conjunto de recursos tecnológicos e de computação, desde os usados para a geração básica de dados, até os relacionados às complexas redes de comunicação existentes nos processos de uso da informação (VELLOSO, 2004, p. 44).

Velloso (2004) ainda diz, que a organização de dados (nomes, palavras, números, sons, imagens) deve ser de suma confiabilidade e capaz de dar um formato ou sentido a algo que interessa a alguém. E acredita que, em qualquer organização, as informações são essenciais para o processo de tomada de decisão e, portanto, seu conjunto de dados deve ser confiável.

É importante ressaltar a diferença conceitual entre dado e informação. Segundo Davenport e Prusak (1998, p. 3), os dados retratam apenas parte do que aconteceu; não proporcionam um julgamento ou explicação ou base para ações sustentáveis. Eles são uma matéria-prima importante para a criação de informações. Portanto, a informação é o dado que funcionam, processam e inserem num cenário. Os autores alegam que se deve considerar a informação como dados que fazem diferença (DAVENPORT; PRUSAK, 1998, p. 4).

Jamil (2001, p. 161) salienta: a informação é algo que requer mais trabalho pois é trabalhosa. Geralmente envolve várias medições e a aquisição de dados relevantes, como o do ambiente em que a medição é realizada.

Goleman et al. (2009) enfatiza que estamos na era da informação e que a TI tem influência em cada aspecto de nossas vidas, e surpreendentemente e inevitavelmente gera leve impacto para alguns e um impacto surpreendente para outros.

Para entender como os sistemas de gestão afetam a organização empresarial, é necessário colocar os sistemas em contexto. Isso significa que é preciso se fazer uma análise da empresa antes de visualizar as alterações. Melhorar os sistemas de gestão não difere de aperfeiçoar outros aspectos da empresa, começando com uma avaliação, promovendo ações específicas para remover barreiras e criar novas oportunidades (LAURINDO; ROTONDARO, 2011).

\subsubsection{Gestão do Marketing Agrícola ou Rural}

Segundo Batalha e Silva (1995, pg. 38) desde a criação da ABMR (Associação Brasileira de Marketing Rural), na década de 1970, o marketing rural é amplamente conhecido no Brasil. Em 1984, foi realizada a primeira conferência da ABMR, que aprofundou e ajudou a identificar problemas na área. Na época, o marketing rural era definido como aquele aplicável as empresas do setor agropecuário. 
De acordo com Megido e Xavier (1998) o marketing rural é uma ferramenta valiosa que responde de maneira efetiva e eficaz às tendências percebidas de mudanças das empresas agrícolas. Por exemplo, na avaliação correta e rápida da demanda do mercado e da demanda do consumidor, é dada mais ênfase aos produtos com alto valor agregado para obter mais nutrição e saúde por meio de mais serviços. O marketing rural é uma das mais recentes áreas de marketing diretamente relacionadas aos negócios agrícolas, que inclui produtos, serviços e atividades nas áreas rurais (MEGIDO e XAVIER, 1998).

Determinar a origem e a demanda do mercado de acordo com o comportamento, a finalidade e os objetivos da empresa, seu desenvolvimento e eficácia são tarefas do marketing (VIEIRA 1994).

A Associação Brasileira de Marketing Rural e Agronegócio - ABMRA usa como sinônimo de "comunicação rural" toda e qualquer organização rural, seja caracterizada por uma pequena unidade de agricultores direcionada para o mercado interno ou por uma grande indústria agrícola voltada para o mercado externo (ABMRA, 2017).

Comparado a outros métodos de marketing, o papel do marketing rural no processo de gestão da propriedade rural tende a assumir cada vez mais complexidade e diferenças. Segundo Vieira (1994), o marketing rural começa da "porteira" para dentro das organizações rurais. $\mathrm{O}$ fundamento do marketing rural é tomar o mercado como ponto de partida, focar na busca da satisfação do consumidor e usar o marketing integrado como um meio de lucrar com a satisfação do consumidor.

O marketing rural utiliza o Mix de Marketing da organização rural, ou seja, o seu produto, seu local de distribuição, sua promoção e o seu preço. Independentemente da organização rural, esses quatro elementos são a base de toda e qualquer ação relacionada à organização rural com o mercado.

De acordo com Tejon e Xavier (2009), para fazer Marketing Rural é necessário expandir o foco. É preciso expandir o pensamento estratégico, e as análises de toda a cadeia produtiva, em que está inserida, afim de aumentar a criatividade e a inovação no planejamento executado - bem como sua substância para o longo prazo e sua força tático-operacional no presente. Ele definiu o Marketing Rural como aquele Marketing aplicável às empresas do setor agropecuário. 


\subsubsection{Gestão da produção}

$\mathrm{Na}$ afirmação de Contador (2010), a produtividade é um dos princípios mais importantes para um empreendimento, atualmente em conjunto com a qualidade, formando um binômio que pode trazer à organização a competitividade mais efetiva em face a concorrência. Combinar alta produtividade a alta qualidade faz com que se possa obter ganhos extraordinários em termos de redução de custos ou em ganho de valor do produto em frente ao mercado consumidor.

Produção refere-se ao processo de aquisição de qualquer elemento (denominado produto) que seja considerado o objetivo da empresa. (CONTADOR, 2010, p. 105). Para ele a produtividade é calculada pela relação entre os resultados da produção real e os recursos de produção aplicados a ela (produção / recursos) (CONTADOR, 2010, p. 106). Alguns exemplos de medida de produtividade são peças/hora-máquina, toneladas produzidas/homem-hora e toneladas de soja/hectare-safra.

Rocha (2008) explica que as empresas procuram constantemente racionalizar seus trabalhos, na esperança de realizar as atividades da melhor maneira possível, de modo a superar seus concorrentes. Isso pode ser explicado em grande parte pela concorrência acirrada, causada pela globalização e a decorrente competição em âmbito mundial. Os administradores que não andaram seguindo o rumo da alta produtividade, certamente não sobreviveram a esta nova realidade econômica. Como resultado, as empresas que adotaram a mecanização e automação do processo produtivo certamente as superarão ou as destruirão.

Também é importante observar que a área de produção não promove apenas o desenvolvimento da empresa. Rocha (2008) assegura que, para alcançar bons índices de produtividade, além da força de trabalho qualificada, que executa todas as tarefas necessárias corretamente, devem haver recursos financeiros suficientes para atender ao investimento necessário. Portanto, outras áreas estratégicas da empresa como finanças, administração e recursos humanos, precisam atuar juntamente a área de produção para atingir plenamente todos os objetivos da empresa.

\subsubsection{Gestão ambiental}

A responsabilidade ambiental já deixou de ser uma mera opção para as empresas que desejam se desenvolver e conquistar os consumidores. Tachizawa (2011) afirma que hoje existe um novo contexto econômico, mobilizado pela globalização, onde os consumidores 
mostram-se a cada dia mais informados e conscientes do poder que têm de exigir das empresas, um comportamento ecologicamente correto na obtenção de seus produtos, ou na prestação de seus serviços. Desta forma, a gestão ambiental tornou-se um importante instrumento para a criação de diferenciais competitivos em empresas, independentemente do ramo de atividade em que atuem.

Para Donaire (2012, p. 28), a preocupação ecológica traz uma nova perspectiva sobre o gerenciamento de recursos naturais que pode simultaneamente atingir a eficácia e a eficiência das atividades econômicas e manter a diversidade e estabilidade ambiental. Neste sentido, entende-se que é possível conciliar os interesses econômicos da organização, com os interesses ambientais exigidos pela sociedade consciente da necessidade de preservação do meio em que vive.

Aligleri, Aligleri e Kruglianskas (2009) fazem menção a práticas responsáveis em propriedades rurais. Para os autores, o agronegócio brasileiro tem aparecido bastante frágil frente às exigências cada vez maiores em relação a boas práticas ambientais. Grandes exigências e denúncias têm sido feitas por organizações não governamentais, consumidores, países importadores e concorrentes com relação a pouca preocupação do setor agropecuário, quanto às consequências de suas atividades para o meio ambiente. No entanto, os autores enfatizam que esta é também uma oportunidade, mediante a qual o setor pode aumentar a sua credibilidade e sendo assim, a adoção de novas práticas, transformando o problema em uma grande vantagem competitiva.

Almeida (2010) afirma que a agropecuária sofreu um processo intensivo de modernização nos últimos anos, o que permitiu um aumento de grande escala em produção e produtividade dos mais variados produtos do setor. No entanto, esta modernização, motivada pelos ganhos econômicos e ampliação dos índices de produtividade, fez com que as propriedades rurais elevassem o uso de diversos produtos químicos e insumos industrializados, muitas vezes danosos ao meio ambiente e até mesmo ao ser humano. Neste sentido, o autor explica que surgiram inúmeras correntes, defendendo o emprego de técnicas mais sustentáveis no setor, culminando na criação e adoção de legislação ambiental mais rígida, que garantisse a adoção de boas práticas no setor.

Em menção a técnicas eficientes e em plena difusão entre as propriedades rurais brasileiras, Aligleri, Aligleri e Kruglianskas (2009) citam o tratamento correto de dejetos de animais, como uma prática sustentável, que traz benefícios ecológicos, além de retorno econômico para o produtor rural. Conforme explicam, a técnica consiste, basicamente, em captar os gases formados pela fermentação dos dejetos de animais, por meio da instalação de 
biodigestores, e utilizando-os para gerar energia na propriedade ou para a comercialização. Além disso, a técnica resulta também em biofertilizante, formado pela matéria oriunda da fermentação dos dejetos. Este, por sua vez, pode ser utilizado na adubação de lavouras, resultando em ótimos ganhos de produtividade.

\footnotetext{
A ideia da agricultura e pecuária sustentável torna-se presente e discutida na sociedade brasileira pois sabe-se que a adoção de melhores práticas agrícolas e o cumprimento das normas são o meio pelo qual a empresa rural e o produtor podem contribuir para o desenvolvimento socioambiental do país (ALIGLERI; ALIGLERI; KRUGLIANSKAS, 2009, p. 53).
}

Obviamente, ignorar a questão ambiental não é mais uma escolha disponível aos empreendimentos rurais. Os consumidores e outros participantes do mercado, estão cada vez mais exigentes e prestando mais atenção às práticas ambientais. A atitude de responsabilidade ambiental e práticas ambientalmente responsáveis fazem com que a pressão aumente a cada dia. É preciso enfrentar esse problema não apenas como mais um requisito à viabilidade da atividade rural, mais também como uma oportunidade de destacar o seu produto, para entrar nos mercados mais meticulosos e ávidos por produtos obtidos sobre a base do respeito com o ambiente em que são produzidos.

\subsection{Etapas da Gestão Rural}

A característica da gestão de uma propriedade rural é feita pelo planejamento, organização, direção e controle das atividades financeiras, para auxiliar nas tomadas de decisões. Portanto, o produtor pode gerenciar sua fazenda, maximizando seu rendimento e minimizando os seus custos, o que pode fazer com que ele alcance melhores resultados financeiros. As quatro funções podem ser vistas a seguir na figura 2. 


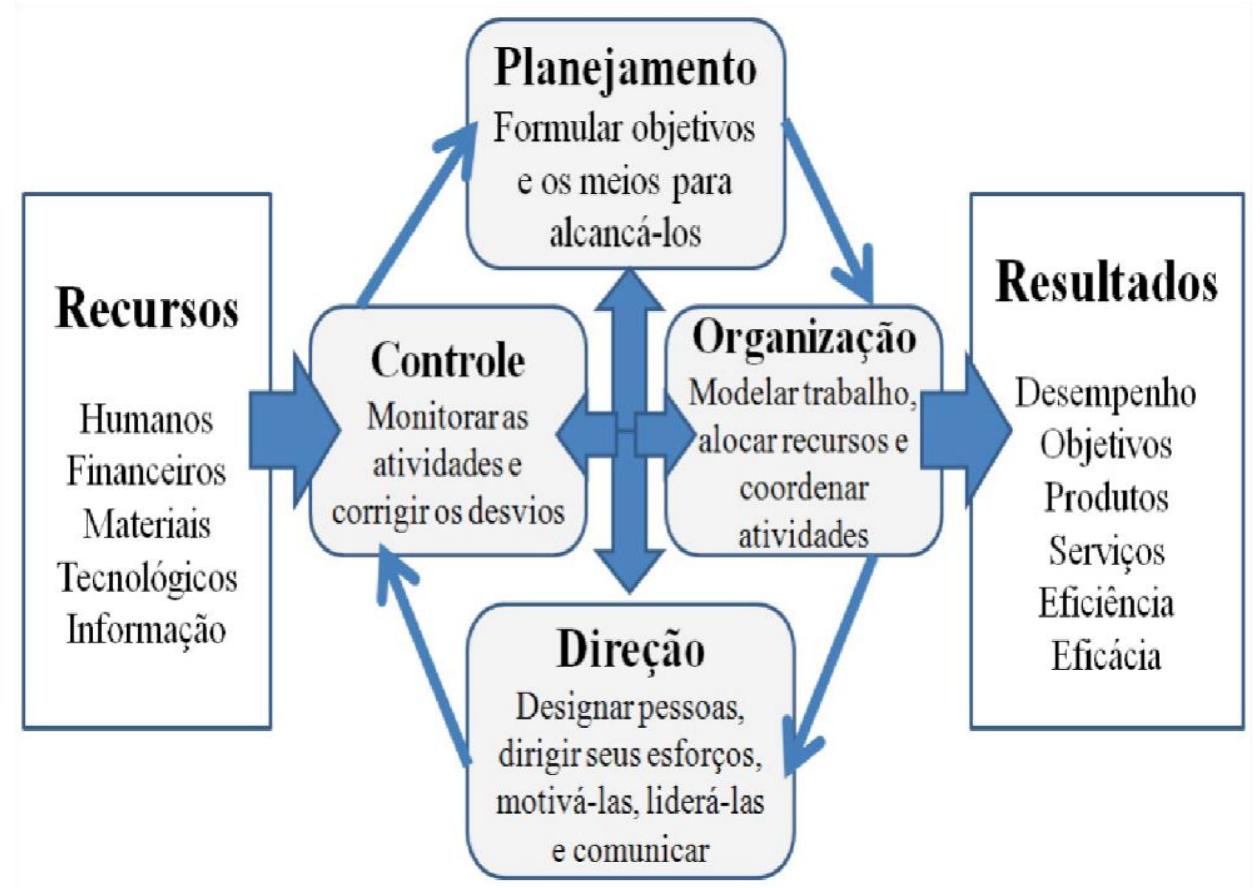

Figura 2- As quatro funções do administrador Fonte: Chiavenato, 2000.

De acordo com Godinho (2015), acredita-se que a taxa de utilização da gestão da propriedade rural seja baixa. Deve-se ressaltar que a falta de gestão, ou a necessidade dela, são fatos importantes a serem observados, porque na verdade, raramente se encontra sua aplicação nessas propriedades.

Nesta perspectiva, Silva, Dias e Lima (2011) acreditam que o uso de melhores condições de produção se torna essencial para alcançar maiores níveis de produtividade e lucratividade. Assim, é necessário monitorar o processo de profissionalização da agricultura com base no conceito de eficiência produtiva.

\subsubsection{Planejamento}

Planejamento é considerado a função principal desempenhada dentro do processo administrativo.

O planejamento é a primeira função administrativa, vindo antes da organização, direção e controle. Planejamento refere-se a esclarecer a missão organizacional e estabelecer as metas da organização, e os meios necessários para alcançá-las com máxima eficiência e eficácia (CHIAVENATO,2004 p. 209). 
Segundo Maximiano (2002 p.105), o planejamento é uma ferramenta usada por indivíduos e organizações para gerenciar relacionamentos com o futuro. Esta é uma aplicação específica do processo de tomada de decisão.

A necessidade do planejamento não se limita ao cumprimento das metas organizacionais. Ele também é necessário para determinar os métodos e os tipos de controle que serão necessários (SILVA, 2009).

Planejar significa basear-se em um método, plano ou lógica para considerar antecipadamente metas, planos e ações. O planejamento gera planos, que determinam estratégias, diretrizes táticas ou procedimentos, de maneira racional para atingir os objetivos determinados (MORAES, 2001).

Segundo Silva (2009), a importância do planejamento está em sua habilidade de indicar um procedimento consistente para atingiras metas esperadas. $O$ planejamento é baseado no entendimento das metas esperadas, de recursos disponíveis e das possíveis combinações de recursos. Quanto mais profundo for o conhecimento desses fatores maiores serão as chances de se alcançar os objetivos.

Na visão de Leone (1999), outro fator importante no planejamento da produção rural é que é impossível mudar a produção imediatamente, porque, uma vez que um investimento é feito, é preciso esperar o resultado da produção e evacuá-lo rapidamente, mesmo em condições adversas ao mercado, menos que seja possível estocar o produto para aguardar melhores condições de venda.

Aprimorando e complementando a ideia Leone (1999) afirma que essas particularidades resultam no aumento da complexidade do gerenciamento da propriedade rural, que pode ser reduzido usando técnicas gerenciais que garantam sua competitividade a longo prazo.

É importante lembrar que o planejamento da propriedade rural está relacionado aos métodos de produção. Fantin (1986) enfatiza a importância da diversificação na unidade de produção, fato que contribui positivamente para o planejamento da propriedade, representando um mecanismo alternativo para que o agricultor tenha uma segunda, terceira e /ou quarta opção de fonte de renda, sem ser afetado pelas flutuações do mercado ou alguma adversidade climática.

Existem três tipos e níveis de planejamento, sendo eles o planejamento estratégico, o tático (gerencial) e o operacional. Como mostra a Figura 3. 


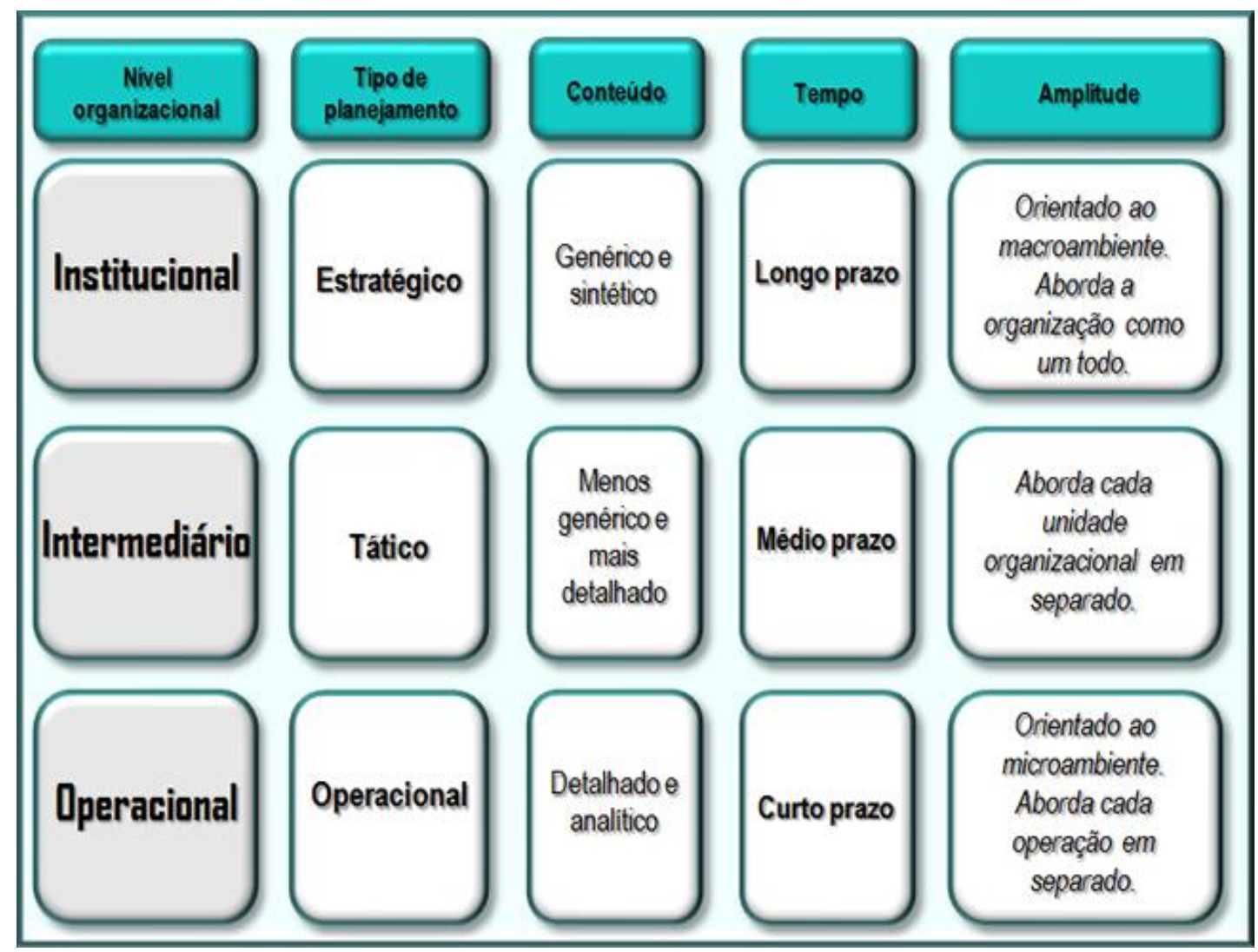

Figura 3- Níveis de planejamento.

Fonte: CHIAVENATO, 2004.

O administrador pode trabalhar sob diferentes níveis de autoridade, ele deve planejar através de diferentes períodos de tempo. Portanto, os objetivos do planejamento devem ser mais específicos no curto prazo e mais abertos no longo prazo. A organização precisa de planos para todos os prazos.

A base da gestão de uma empresa rural é o planejamento estratégico. Assim, o planejamento estratégico é uma ferramenta para prever ações que enfrentam vários fatores que envolvem o ambiente da propriedade rural.

No nível tático, o planejamento é realizado a médio prazo. O nível tático é um conjunto de decisões que envolvem ações limitadas, prazos mais curtos, áreas menores e hierarquia organizacional mais baixa. Dessa forma, pode-se observar que o planejamento tático está relacionado ao planejamento estratégico, e a diferença entre um e outro é a questão de tomada de decisão no interior da organização (CHIAVENATO, 1994 p. 186).

O nível operacional faz referência aos responsáveis pela realização das atividades recomendadas dentro da organização. Nesse nível, o planejamento é executado em pouco tempo. O objetivo é atingir essa meta, monitorando de perto as operações que geram o produto 
final, serviço e trabalho da empresa. Portanto, pode-se concluir que este planejamento consiste em todos os planos de ação do planejamento operacional da empresa (TAJRA, 2006, p.55).

Segundo Maximiano (2004, p.134), o planejamento estratégico é o processo de definição das metas de longo prazo da organização.

Através do planejamento estratégico, as estratégias do ambiente podem ser diagnosticadas e analisadas permitindo que o administrador entenda melhor o futuro de suas atividades. No entanto, com o aumento de riscos e incertezas das empresas rurais e a coexistência de mutações, a dificuldade das empresas rurais em adotar essa tecnologia aumentou. (JANK; LOPES, 1992; NEVES, 1996).

Se a propriedade rural receber o apoio necessário para a tomada de decisões estratégicas, a estrutura do processo de planejamento estratégico será eficiente, eficaz e efetiva.

\subsubsection{Organização}

Na visão de Oliveira (2010) a organização é uma função administrativa que se atenta a administrar todos os recursos da propriedade, para atingir as metas estabelecidas pelo produtor e por sua família. A organização física é responsável pela organização dos registros de dados da propriedade e trata da disposição das áreas e das melhorias.

Uma vez desenvolvidos planos e metas, a gerência deve desenvolver uma maneira organizada de agrupar os recursos físicos e humanos que são fundamentais para alcançar os propósitos da empresa (SILVA, 2009).

Organizar refere-se à distribuição do trabalho, a autoridade (estabelecimento de estruturas hierárquicas e coordenativas) e os recursos na empresa, produzindo a estrutura organizacional, formada pelo total de unidades organizacionais e relações funcionais (OLIVEIRA, 2010).

Com base nas ideias de Garcia Filho (1999), a atividade agrícola e o meio rural apontam como características específicas a complexidade e diversidade de organização e produção. Dado o potencial e as limitações dos produtos inseridos, a complexidade ocorre das maneiras de possível uso do ambiente.

Deve-se destacar que toda a organização não deve se limitar ao interior das unidades de produção agrícola ou mesmo a qualquer produto agrícola específico. É crucial estudar os sistemas de produção, cadeias produtivas, chances de mercado, ver as dinâmicas familiares, respeitando as experiências dos agricultores, cooperando com a organização comunitária e dando valor a educação para atingir o sucesso do empreendimento (DENARDI, 2001). 


\subsubsection{Direção}

A direção é, na maioria dos casos, uma função a ser exercida pelo produtor ou o administrador da propriedade rural (OLIVEIRA, 2010).

De acordo com Silva (2009) a direção deve ser realizada sobre pessoas e não sobre máquinas, benfeitorias, terras ou animais. Em vista disso, para dirigir é necessário agir com recursos humanos, e entender suas relações e comportamentos. Seguindo em suas observações Silva (2009), salienta que a direção ocorre em todos as posições da empresa, nível estratégico, gerencial e operacional. Para liderar com sucesso sua empresa, o empresário rural deverá se basear em três aspectos básicos: motivação, liderança e comunicação.

Sobral et al., (2012) complementa afirmando que a função direção inclui orientação, a motivação, a comunicação e a liderança dos trabalhadores, e se esforça para corresponder seus objetivos com o desempenho da organização. Essa função é responsável pelo desenvolvimento de boas condições de trabalho, propício a um ambiente de cooperação entre os membros da organização e a resolução de quaisquer conflitos que possam surgir.

Alguns estudiosos chamam a função direção de liderança. Contudo, deve-se entender que liderança é uma qualificação da direção, e não pode ser substituída pela função de direção. Pode-se dirigir sem liderança, o que não é a melhor condição. Liderar é uma condução qualificada para tornar a função de direção mais eficiente (SOBRAL et al., 2012).

\subsubsection{Controle}

Para Moraes (2001), controle é verificar se as ações executadas estão de acordo com os planos, ou seja, se estas ações, individuais ou coletivas, e a ação organizacional são realmente guiadas pelas metas estabelecidas.

Complementando essa ideia Silva (2009) entende que o controle é uma atividade importantíssima dentro da empresa rural, pois pode corrigir erros que sejam sanados a tempo, e venha impedir que outras funções da produção sejam danificadas. Um sistema de controle eficiente garante que todas as atividades da empresa prossigam conforme o planejado. Em resumo, o controle tem a função de manter o sistema organizacional dentro de um padrão de comportamento anteriormente definido (SOBRAL et al., 2012). 
Souza e Vieira (1990) expõem a função controle em quatro estágios diferentes: o estabelecimento de padrões, a mensuração do desempenho, a comparação com desempenho obtido com o esperado e a ação corretiva adotada. 


\section{ASPECTOS RELEVANTES DOS AUTORES CITADOS}

O quadro 1 resume as colaborações fornecidas pelos autores abordados neste trabalho.

\begin{tabular}{|c|c|}
\hline Batalha (2001) & $\begin{array}{l}\text { Compreensão do Agronegócio; } \\
\text { Etapas do agronegócio: antes da porteira, dentro da porteira e depois da } \\
\text { porteira; } \\
\text { Implementação dos sistemas de gerenciamento corporativos; }\end{array}$ \\
\hline Silva (2009) & $\begin{array}{l}\text { Administração rural; } \\
\text { Necessidade do planejamento; } \\
\text { Agrupamento dos recursos físicos e humanos pela gerência; } \\
\text { Realização da direção; } \\
\text { Aspectos básicos para liderar com sucesso a empresa; } \\
\text { Sistema de controle eficiente; }\end{array}$ \\
\hline $\begin{array}{c}\text { Santos e } \\
\text { Marion (1996) }\end{array}$ & $\begin{array}{l}\text { Fatores internos e fatores externos da empresa agrícola; } \\
\text { Gestão de empresas rurais; } \\
\text { Principal papel do administrador rural; }\end{array}$ \\
\hline $\begin{array}{l}\text { Lourenzani e } \\
\text { Souza Filho } \\
\quad(2009)\end{array}$ & $\begin{array}{l}\text { Comparação do processo de gestão das propriedades rurais ao processo de } \\
\text { empresas sistêmicas; } \\
\text { Objetivo da administração dos recursos financeiros orçamentários de um } \\
\text { estabelecimento rural; } \\
\text { Atuais desafios impostos pelo mercado; } \\
\text { Registro sistemático das informações contábeis da organização; } \\
\text { Fatores determinantes para o desenvolvimento de sistemas de gestão da } \\
\text { qualidade; }\end{array}$ \\
\hline $\begin{array}{l}\text { Goleman et al } \\
\quad(2009)\end{array}$ & $\begin{array}{l}\text { Avaliação do impacto da Internet nos negócios pelos gestores; } \\
\text { Era da informação; } \\
\text { Processos de negócio; }\end{array}$ \\
\hline Velloso (2004) & $\begin{array}{l}\text { Utilização da Tecnologia da Informação; } \\
\text { Conceito de Tecnologia da Informação; } \\
\text { Confiabilidade da organização de dados; }\end{array}$ \\
\hline $\begin{array}{l}\text { Contador } \\
\text { (2010) }\end{array}$ & $\begin{array}{l}\text { Produtividade relacionada com a qualidade gerando competitividade } \\
\text { efetiva para a organização; } \\
\text { Produtividade em relação ao conjunto dos resultados da produção efetivada } \\
\text { e aplicação de recursos produtivos; } \\
\text { Produção; }\end{array}$ \\
\hline $\begin{array}{l}\text { Aligleri, } \\
\text { Aligleri e } \\
\text { Kruglianskas } \\
\text { (2009) }\end{array}$ & $\begin{array}{l}\text { Práticas responsáveis em propriedades rurais; } \\
\text { Técnicas eficientes e em plena difusão entre as propriedades rurais } \\
\text { brasileiras; } \\
\text { Agricultura e pecuária responsável; }\end{array}$ \\
\hline $\begin{array}{l}\text { Oliveira } \\
\text { (2010) }\end{array}$ & $\begin{array}{l}\text { Organização física; } \\
\text { Referência de organizar; } \\
\text { Estrutura organizacional; } \\
\text { Função da direção; }\end{array}$ \\
\hline $\begin{array}{l}\text { Sobral et al } \\
\text { (2012) }\end{array}$ & $\begin{array}{l}\text { Função direção; } \\
\text { Função do controle; }\end{array}$ \\
\hline
\end{tabular}


Liderar;

Quadro 1 - Aspectos relevantes dos autores citados.

Fonte: Desenvolvido pela Pesquisadora (2020). 


\section{METODOLOGIA}

O projeto de conclusão de curso em questão dispôs-se a avaliar o impacto das ferramentas administrativas nos meios de produção rural com foco na melhoria da gestão destes, de forma que a viabilidade da pesquisa foi confirmada dada à confiabilidade do acervo digital onde foi localizado a respeito da gestão de negócios rurais. A angariação de dados consistiu em constatação do material de interesse nos meios virtuais, bem como em livros, revistas e artigos. Em consonância com Lakatos e Marconi (2001), quanto à técnica de coleta de dados, uma pesquisa pode ser classificada como: documentação direta intensiva, direta extensiva e indireta. A documentação indireta estará relacionada com a pesquisa documental e bibliográfica.

No caso específico desta pesquisa, quanto à técnica de coleta de dados, foi adotada a pesquisa indireta que abrange uma pesquisa bibliográfica, com o propósito de aprofundar os conhecimentos através de artigos científicos, livros, e documentos legais (LAKATOS; MARCONI, 2001).

O presente estudo foi realizado seguindo os critérios da pesquisa aplicada. Segundo Appolinário (2011, p. 146) é realizada com o intuito de "resolver problemas ou necessidades concretas e imediatas".

Após definida a pesquisa, foi realizado em seguida a avaliação do material onde se definiu qual seria o melhor comportamento com base nos propósitos definidos. Deste modo, o resultado foi desenvolvido por meio de análise dos conteúdos teóricos, uma vez que estipula testar hipóteses que comprovaram durante o trabalho a busca através de textos existentes, a compreensão dos autores e verifica de forma criteriosa as informações contidas. Deste modo se empregou a pesquisa bibliográfica descritiva, que dentro da concepção de Castilho, Borges e Pereira (2017, p. 20), "é baseada na consulta de todas as fontes secundárias relativas ao tema que foi escolhido para realização do trabalho".

Uma vez que este trabalho visou avaliar as metodologias aplicadas por outros profissionais em administração rural, pôde-se classificar como sendo de análise qualitativa, haja visto que determinou melhores práticas com base na análise de ideias de acordo com Castilho, Borges e Pereira (2017, p. 18) é a qualidade como prioridade de ideias, coisas e pessoas que permite que sejam diferenciadas entre si de acordo com as suas naturezas.

É necessário ressaltar que dentro do contexto escolhido para análise, houve como objeto de pesquisa, as diversas implicações das decisões tomadas por gestores de regiões agrícolas, delimitando maneiras de se alcançar resoluções assertivas no que compete a gestão 
eficiente das lavouras e plantações, bem como da aplicação efetiva destas para alavancagem dos negócios rurais.

Os objetivos deste trabalho de conclusão de curso se combinam entre exploratórios e explicativos, pois de acordo com Gil (2008 p. 27-28) as pesquisas exploratórias têm como principal finalidade desenvolver, esclarecer e modificar conceitos e ideias, tendo em vista a formulação de problemas mais precisos ou hipóteses pesquisáveis para estudos posteriores [...]. E também explicativas que tratam de pesquisas que têm como preocupação central identificar os fatores que determinam ou que contribuem para a ocorrência dos fenômenos.

Nesta direção, é importante esclarecer que foram selecionados artigos e livros nos sites Google Acadêmico, Universidades Federais de Administração, Associação Brasileira de Marketing Rural e Agronegócio (ABMRA), Associação Brasileira do Agronegócio (ABAG), Biblioteca Pearson entre outros. O critério de seleção utilizado pesquisou materiais em conformidade com as palavras chave: agronegócio", "gestão rural", "administração rural" e "Gerenciamento rural".

Implementa ainda que o material também conteve em grande parte dos itens as expressões chave pré-determinadas, sendo estas: desenvolvimento rural; planejamento rural; agricultura sustentável; notoriamente rejeitando textos que não apresentaram os já definidos termos e ou não proporcionaram conteúdo indubitável.

O método aplicado foi hipotético dedutivo, já que parte de uma hipótese que foi confirmada ou refutada. Nesta direção, o termo foi explicado por Mezzaroba e Monteiro (2009, p. 68-69) onde formulou-se uma hipótese, testando a ocorrência de fenômenos abrangidos pela hipótese. São as variáveis que persistem como válidas resistindo às tentativas de falseamento. 


\section{RESULTADOS E DISCUSSÕES}

Os resultados apresentados pela pesquisa expõem a potencialização do trabalho desenvolvido na gestão de propriedades rurais com o uso da administração. O serviço administrativo do proprietário rural na busca da obtenção de lucros e sustentabilidade, são consequências do alinhamento da gestão com o planejamento.

Por conseguinte, foi abordado nos objetivos específicos, a potência do agronegócio no país, a identificação dos modelos de Gestão Rural e a descrição das etapas do processo. Diante disso o agronegócio no Brasil desfruta de terras férteis e produtores rurais com conhecimento e tecnologia agrícola que transformam recursos em produtos, em um negócio responsável por um terço do Produto Interno Bruto (PIB), e que emprega milhões de trabalhadores, contribuindo expressivamente com o mercado de exportação.

Segundo Lourenço (2009), o agronegócio para a economia brasileira é de extrema importância, pois esse setor é considerado como o maior mercado mundial, e coloca o nosso país em destaque na área de exportação.

Ademais, na identificação dos modelos de gestão a Administração Rural atua no auxílio para as tomadas de decisões aliadas as seguintes Gestões: Financeira, Qualidade, Processos e Tecnologia da Informação, Marketing Agrícola, Produção e Ambiental.

Em síntese, temos na Gestão Financeira o controle dos custos que auxiliam o planejamento do negócio. A Gestão de Qualidade é verificado os serviços na qualidade de produção da área agrícola, e a Gestão de Processos e da Tecnologia da Informação é baseada em componentes tecnológicos que favorecem os processos aliados a internet e a sistemas de informação.

Desta forma na Gestão de Marketing Agrícola, busca-se a satisfação do consumidor, satisfação essa relacionada às tendências do mercado, seguida da Gestão de Produção que almeja constantemente alcançar bons índices de produtividade. A Gestão Ambiental em tempos de sustentabilidade no ramo do agronegócio é de essencial importância, pois esta área é responsável por reduzir os impactos ambientais na natureza.

Em contrapartida temos as etapas da Gestão Rural que enumeramos como: Planejamento, Organização, Direção e Controle, que formam os pilares dos resultados convincentes das atividades. O Planejamento é a função principal do processo, seguida da Organização, que administra os recursos da propriedade aliada a Direção, que é exercida pelo 
produtor rural e por fim temos o Controle, que verifica se as ações estão de acordo para possíveis correções, de maneira que não prejudiquem o processo agrícola.

A hipótese levantada neste estudo foi: o que fazer para melhorar o desenvolvimento da gestão rural, particularmente, da agricultura nas propriedades rurais? Atualmente o agronegócio é trabalhado de forma diferente de quando ele foi iniciado em meados dos anos 80. Com a globalização e a era da internet, foram criadas novas realidades obrigando os produtores agrícolas a se atualizarem frente as mudanças constantes do mercado, dentre elas a era digital, a preservação do meio ambiente e sustentabilidade.

Diante disso, uma das alternativas seria obter procedimentos e processos sistematizados para administração rural com o uso de softwares de computadores e aplicativos para celulares. Com esses sistemas o produtor teria dados em tempo real o que facilitaria sua produção, controle de vendas, estoque e logística. Isso aliado a avanços tecnológicos desde a previsão do clima, uso do solo, e fontes alternativas para aumentar produção e controle de pragas, minimizando custos e maximizando rendimentos, pois todo empreendimento por mais simples que seja, requer o uso de algum sistema de informação, e na área rural não é diferente.

Outra opção é trabalhar a motivação e o bem-estar sociointerativo da equipe que o administrador rural estiver a frente. Ele deve se atentar a um ambiente de trabalho onde seus colaboradores se sintam insatisfeitos e desmotivados, o que por consequência, não trará boa produtividade. Assim, afirma Robbins (2005, p. 135) “a motivação pode ser definida como o processo responsável pela intensidade, direção e persistência dos esforços de uma pessoa de uma determinada meta". 


\section{CONSIDERAÇÕES FINAIS}

Considerando tudo o que foi explanado, chega-se a conclusão de que o trabalho realizado sobre a importância da administração no desenvolvimento de propriedades rurais, atingiu o objetivo esperado. Identificamos que é necessário realizar uma gestão bem estruturada, com planejamento do negócio visando o controle gerencial e financeiro com profissionalismo, buscando diminuir os custos no fator de produção e aumentando sua rentabilidade.

A tecnologia é vista como uma grande aliada no processo de desenvolvimento do setor agrícola em nosso país. Expandir essa área tão valiosa é um desafio que os produtores rurais enfrentam diariamente, pois a demanda mundial por alimentos aumenta conforme o crescimento populacional, além da globalização e a competição com o mercado externo.

O Brasil se destaca diante de outros países, pois possui terras produtivas para o agronegócio com recursos naturais que favorecem esse cenário, onde podemos aplicar a sustentabilidade com consciência, e respeito com as práticas de preservação do meio ambiente, o que contribui para a continuidade desse setor.

Conclui-se que a nova visão adotada pelos produtores voltadas ao mercado e rentabilidade como empreendimento rural, melhorou expressivamente a qualidade do trabalho desenvolvido. Tornou-se imprescindível a discussão de como e onde será desenvolvido, bem como, para quem será oferecido o serviço, propondo melhorias e adequações nos processos. $\mathrm{O}$ uso contínuo da administração com ferramentas gerenciais desde objetivos, estratégias e metas a serem alcançadas, tem por finalidade nortear todo o processo do empreendedor rural, e consequentemente, o aumento de sua produtividade, impactando positivamente nos resultados e na capitalização de lucros. 


\section{REFERÊNCIAS}

ALIGLERI, Lilian; ALIGLERI, Luiz Antônio; KRUGLIANSKAS, Isak. Gestão socioambiental: responsabilidade e sustentabilidade no negócio. São Paulo: Atlas, 2009.

ALMEIDA, Jalcione. A modernização da agricultura. Porto Alegre: UFRGS, 2010.

AMARAL, A. M. M; DANTAS, L. O. Planejamento e gestão na agricultura familiar, 2010. APPOLINÁRIO, Fabio. Dicionário de Metodologia Científica. 2. ed. São Paulo: Atlas, 2011. $295 \mathrm{p}$.

ARAÚJO, Massilon J. Fundamentos do agronegócio. São Paulo: Atlas, 2003.

ARAÚJO, Massilon J. Fundamentos de agronegócios. 2. ed. São Paulo: Editora Atlas, 2005.

ASSOCIAÇÃO BRASILEIRA DO AGRONEGÓCIO, ABAG. Agronegócio. Disponível em: <http://www.abagrp.org.br/agronegocioConceito.php>. Acesso em: 7 mai. 2019.

ASSOCIAÇÃO BRASILEIRA DO AGRONEGÓCIO, ABAG. Agronegócio: quem conhece valoriza, $2009 . \quad$ Disponível em: <https://www.google.com/url?sa=t\&source=web\&rct=j\&url=http://www.abagrp.org.br/pagin a/download/7928\%3Fforce\%3Dn\&ved=2ahUKEwizrJDIp9zpAhXQK7kGHRsxDEYQFjAEe gQIAxAB\&usg=AOvVaw0tHYkGPbwTordOEAzopHwH>. Acesso em: 07 mai. 2019.

ASSOCIAÇÃO BRASILEIRA DE MARKETING RURAL E AGRONEGÓCIO, ABMRA. 7 Pesquisa hábitos do produtor rural, 2017. Disponível em: <https://pt.slideshare.net/mobile/VeronicaRRSouza/pesquisa-hbitos-do-produtor-rural-2017abmra>. Acesso em: 15 abr. 2020.

BARROS, Carina; MONTEIRO, Alda Lúcia Gomes; PRADO, Odilei Rogerio. O gerenciamento da empresa rural. Milkpoint, São Paulo, fev. /2011. Disponível em: <http://www.farmpoint.com.br/radares-ecnicos/gerenciamento/o-gerenciamento-daempresa-rural-69847n.aspx>. Acesso em: 17 abr. 2020.

BATALHA, M. O. Gestão agroindustrial. 2. ed. São Paulo: Atlas, 2001.

BATALHA, M.O. Gestão agroindustrial: GEPAI: Grupo de Estudos e Pesquisas Agroindustriais, v. 2, 3.ed., São Paulo: Atlas, 2001.

BATALHA, M.O. Gestão agroindustrial: GEPAI: Grupo de Estudos e Pesquisas Agroindustriais, v. 1, 3.ed., São Paulo: Atlas, 2007.

BATALHA, M. O. Gestão agroindustrial. v. 2, 5. ed., São Paulo: Atlas, 2009.

BATALHA, M.O; SILVA, A.L. Marketing e agribusiness: um enfoque estratégico.

Revista de Administração de Empresas. São Paulo, v.35. n.5.p.30-39, 1995. 
BATEMAN, T.S.; SNELL, S.A. Administração: construindo vantagem competitiva. São Paulo: Atlas, 1998. 539 p.

BIALOSKORSKI NETO, S. Agribusiness cooperativo: Economia, doutrina, e estratégias de gestão. Piracicaba: ESALQ/USP, 1994.

BREITENBACH, Raquel. Gestão Rural no contexto do agronegócio: desafios e limitações. Revista Desafio On-line, v.2, n.2, Mai/Ago 2014. Disponível em: https://periodicos.ufms.br/index.php/deson/article/view/1160/753>. Acesso em 08 jul. 2020.

BRUM, A.J. Desenvolvimento econômico brasileiro. 24. Ed. Ijuí: Unijuí, 2005.

CALlADO, Antônio A. Cunha. Agronegócio. 1. ed. São Paulo: Atlas, 2006.

CALLADO, Antônio André Cunha; CALLADO, Aldo Leonardo Cunha. Custos: Um desafio para gestão do agronegócio. 2009. Disponível em: <http://www.biblioteca.sebrae.com.br/ bds/bds.nsf/69a5e2bb919eaf2e832574b0004bda60/7dc55898743cf66483256f6b00617007/\$F ILE/NT000A2306.pdf >. Acesso em 15 mar. 2020.

CASTILHO, Auriluce Pereira; BORGES, Nara Rúbia; PEREIRA, Vânia Tanús. Manual de Metodologia Científica 3. ed.: Itumbiara: ILES/ULBRA,2017. Disponível em: <http://www.ulbra.br/itumbiara/espaco-academico/manual-de-metodologia-cientifica $>$. Acessado em: 1 jun. 2019.

CHIAVENATO, Idalberto. Administração: teoria, processo e prática. 2. ed. São Paulo: Makron Books, 1994.

CHIA VENATO, Idalberto. Introdução à teoria geral da administração. 6. ed. Rio de Janeiro: Campus, 2000.

CHIAVENATO, Idalberto. Administração nos Novos Tempos. São Paulo: Campus, 2004.

CONTADOR, José Carlos. Gestão de operações: a engenharia de produção a serviço da modernização da empresa. 3. ed. São Paulo: Blucher, 2010.

CONTINI, Elisio. Dinamismo do Agronegócio Brasileiro. Disponível em: < http://www.agronline.com.br/artigos/artigo>. Acesso em: 07 jun. 2019.

CREPALDI, Silvio Aparecido. Contabilidade Rural: Uma abordagem decisorial. 7 ed. São Paulo: Atlas, 2012.

DAVENPORT, T.H. Reengenharia de processos: como inovar na empresa através da tecnologia da informação. Rio de Janeiro: Campus, 1994.

DAVENPORT, T.H.; PRUSAK, L. Conhecimento empresarial: como as organizações gerenciam o seu capital intelectual. Rio de Janeiro: Campus, 1998.

DEMING, W. E. Qualidade: a revolução da administração. Rio de Janeiro: Marques Saraiva, 1982. 
DENARDI, R. A. Agricultura familiar e políticas públicas: alguns dilemas e desafios para o desenvolvimento rural sustentável. Agroecol. E Desenv. Rur. Sustent., Porto Alegre, v. 2, n. 3, jul/set. 2001.

DONAIRE, Denis. Gestão ambiental na empresa. 2. ed. São Paulo: Atlas, 2012.

FALCONI, Vicente. TQC: Controle da Qualidade Total (no estilo Japonês). Rio de Janeiro: Bloch, 1992.

FANTIN, E. Diversificação: um segredo da pequena unidade produtiva. Revista Brasileira de Extensão Rural. V. 8, n. 1, p. 10-11. 1986.

FERNANDES, Bernardo M. Cercas do latifúndio: Agronegócio é o novo nome fantasia da agricultura capitalista, que tenta modernizar sua imagem, mas reforça a exploração e concentração de terra. Disponível em: <http://www.planetaportoalegre.net. >. Acesso em 7 mai. 2019.

FRANCISCHETTI JÚNIOR, S. C.; ZANCHET, A. Perfil contábil-administrativo dos produtores rurais e a demanda por informações contábeis. V. 6, N. 11, 2006. Disponível em: <e-revista.unioeste.br/index.php/csaemrevista/article/download/369/280 >. Acesso em: 17 abr. 2020 .

GARCIA FILHO, D. P. Guia metodológico -Diagnóstico de sistemas agrários. Brasília: Projeto de cooperação técnica Incra/FAO (UTF/BRA/051/BRA), 1999, p.58.

GIL, Antonio Carlos. Como elaborar projetos de pesquisa. 5. ed. São Paulo: Atlas, 2008.

GODINHO, Ricardo Ferreira. A gestão de empresas rurais. Milkpoint, São Paulo, jun./2015. Disponível em: <http://www.milkpoint.com.br/radar-tecnico/gerenciamento/ a-gestao-de-empresas-rurais-95522n.aspx>. Acesso em: 18 mai. 2020.

GOLEMAN, D. et al. Tecnologia e gestão da informação. Tradução de Roberto Miranda Rocha Socorro. Rio de Janeiro: Elsevier, 2009.

HOFFMANN, Rodolfo. Administração da Empresa Agrícola. São Paulo: Pioneira, 1987.

JAMIL, G. L. Representando a TI na empresa moderna: atualizando a gestão com a tecnologia da informação. Rio de Janeiro: Axcel Books do Brasil, 2001.

JANK, M.S.; LOPES, M.R. O setor leiteiro, a intervenção do Estado e o MERCOSUL: análises e propostas de estratégias e políticas. São Paulo: ABPLB, 1992.

JURAN, J. M. \& GRYNA, Frank M. Controle da Qualidade Handbook. Conceitos, políticas e filosofia da qualidade. Tradução Maria Cláudia de Oliveira Santos. Revisão técnica TQS Engenharia. São Paulo: Makron, McGraw-Hill, 1991 v.1.

LAURINDO, F.J.B.; ROTONDARO, R.G. Gestão integrada de processos e da tecnologia da informação. 1. ed. - 3. reimpr. - São Paulo: Atlas, 2011. 
LAKATOS, E. M.; MARCONI, M. A. Fundamentos metodologia científica. 4.ed. São Paulo: Atlas, 2001.

LAKATOS, E. M.; MARCONI, M. A. Fundamentos de Metodologia Cientifica. 5. Ed. São Paulo: Atlas, 2003.

LEONE, N. M C P. G.; As especificidades das pequenas e médias empresas. Revista de Administração. São Paulo, v. 34, n. 2, p. 91-94, abril/junho 1999.

LOURENÇO, Carlos; DE LIMA, Barbosa. Evolução do agronegócio brasileiro, desafios e perspectivas. Observatorio de la Economía Latinoamericana. Número 118, 2009.

Disponível em: <http://www.eumed.net/cursecon/ecolat/br/>. Acesso em: 05 mar. 2020.

LOURENÇO, Carlos; DE LIMA, Barbosa. Evolução do agronegócio brasileiro, desafios e perspectivas. Observatório de la Economía Latinoamericana. Número 118, 2009.

Disponível em: <http://www.eumed.net/cursecon/ecolat/br/>. Acesso em: 15 abr. 2020.

LOURENZANI, Luiz; SOUZA FILHO, Meirelles; FERENC, Istvan. System thinking: critical thinking skills for 1990s and beyond. System Dynamics Review. New York: John Willey \& Sons Ltd., v. 9, n. 2, p. 113-133, 1993.

LOURENZANI, Wagner Luiz; FILHO, Hildo Meirelles de Souza. Gestão integrada para a agricultura familiar. In: FILHO, Hildo Meirelles de Souza; BATALHA, Mário Otávio. Gestão integrada da agricultura familiar. São Carlos: Universidade Federal de São Carlos, 2009.

LIMA, Arlindo Prestes de; et al. Administração da unidade de produção familiar: modalidades de trabalho com agricultores. Ijuí: Ed. Unijuí, 2005.

MARION, José Carlos. Contabilidade Rural. São Paulo: Atlas, 2007.

MARTINS, E. Contabilidade de custos. 9. ed. São Paulo: Atlas, 2003.

MARTINS, Eliseu. Contabilidade de Custos. São Paulo: Atlas, 2010.

MAXIMIANO, Antonio César Amaru. Teoria Geral da Administração. São Paulo: Atlas, 2002.

MAXIMIANO, Antonio César Amaru. Fundamentos de Administração. São Paulo: Atlas, 2004.

MATTAR, F.N. Pesquisa de marketing. Edição compacta. 4. ed. São Paulo: Atlas, 2007.

MEGIDO, J.L; XAVIER, C. Marketing \& agribusiness. São Paulo: Atlas, 1998.

MENDES, J.T.G; PADILHA, J.B. Agronegócio: uma abordagem econômica. São Paulo: Pearson Hall, 2007. 
MERLI, G. Eurochallenge - The TQM aproack to capturing global markets. Reino Unido: European Foundation for Quality Management, 1993.

MEZZAROBA, O.; MONTEIRO, C. S. Manual de metodologia da pesquisa em direito. 5.ed. São Paulo: Saraiva, 2009.

MORAES, Anna Maris Pereira de. Iniciação ao estudo da Administração. 2. ed. São Paulo: Makron Books, 2001.

NEVES, M. F. A busca do comprometimento organizacional para o processo de planejamento estratégico. In: Anais do I SEMEAD, São Paulo, FEA/USP, p.12-32, outubro/1996.

NOGUEIRA, Antônio Carlos Lima. Agricultura: As Perspectivas do Agronegócio Brasileiro até 2024.2 Disponível em: $<$ https://www.google.com/url?sa=t\&source=web\&rct=j\&url=https://downloads.fipe.org.br/pu blicacoes/bif/bif42636.pdf\&ved=2ahUKEwib1Ke9ufoAhUzEbkGHeN2BV4QFjAAegQIAR AB\&usg=AOvVaw0QqdcckXx5ZA0eUS3tZZnQ>. Acesso em: 08 mar. 2020.

OCDE-FAO Perspectivas agrícolas 2015-2024. Alimentação em foco, 2015. Disponível em: $<$ https://www.google.com/url?sa=t\&source=web\&rct=j\&url=https://alimentacaoemfoco.org.b r/wp-content/uploads/2016/11/OCDE_FAO_Perpectivas-Agr\%25C3\%25ADcolas-20152024.pdf\&ved=2ahUKEwj18MSAldzpAhXqEbkGHS7qDfEQFjAAegQIARAB\&usg=AOvV aw2V2w1VLN6aweCkUR0rj_Vc>. Acesso em: 8 mar. 2020.

OLIVEIRA, L. M.; PEREZ JUNIOR, J. H.; SILVA, C. A. S. Controladoria estratégica. 3. ed. São Paulo: Atlas, 2005.

OLIVEIRA, N.C. Contabilidade do Agronegócio. 2 ed. Juruá Editora. Curitiba, 2010.

PEREIRA, Maria I.; SANTOS, Sílvio A. Modelo de Gestão: uma análise conceitual. São Paulo: Pioneira-Thomson Learning, 2001.

PROCÓPIO, A. M. A utilização de modelos decisórios contábeis pelo pequeno e médio produtor rural. Um Estudo na região de Ribeirão Preto. Dissertação de Mestrado em Contabilidade. São Paulo: FEA/USP, 1997.

RENAI. A Rede Nacional de Informações sobre o Investimento. O Setor de Agronegócio no Brasil: Histórico e Evolução do Agronegócio Brasileiro. Disponível em: < http://investimentos.desenvolvimento.gov.br/intern>. Acesso em: 07 jun. 2019.

ROBBINS, S. P. Comportamento Organizacional. ed. 11, São Paulo: Pearson Prentice Hall, p 135, 2005.

ROCHA, Duílio Reis da. Gestão da produção e operações. Rio de Janeiro: Ciência Moderna, 2008.

SANTOS, G.J.; MARION, J.C. Administração de custos na agropecuária. 2 ed. São Paulo: Atlas, 1996. $140 \mathrm{p}$. 
SEIBEL, Felipe. O novo salto do agronegócio. Exame. Disponível em: < http://www.portalexame.abril.com.br/berto/anuarioagrone>. Acesso em: 07 jun. 2019.

SILVA, E. Carlos Carneiro da; DIAS, Renato de Lima; LIMA, Marcelo Mencarini. Manual do software RuralPro 2010: gestão de propriedade rurais. Brasília: Emater/DF, 2011.

Disponível em: <http://otca.info/gef/uploads/e7ccb-EMATER.pdf>. Acesso em: 17 abr. 2020.

SILVA, R. A. G. Administração Rural: Teoria e Prática - 2º Edição. Curitiba: Juruá, 2009. p. 194.

SOBRAL, F.; PECI, A.; CARAVANTES, G. C.; SILVA, R. Administração Geral - São Paulo, SP: Pearson Prentice Hall, 2012.

SOUZA, R.; GUIMARÃES, J. M. P.; VIEIRA, G. Administração da fazenda. 3 ed. Rio de Janeiro: Globo, 1990. p. 221.

STEFANELO, Eugênio L. Agronegócio brasileiro: propostas e tendências. Revista FAE Business. n 3, set. 2002.

TACHIZAWA, Takeshy. Gestão ambiental e responsabilidade social corporativa: estratégias de negócios focadas na realidade brasileira. 7. ed. São Paulo, Atlas, 2011.

TAJRA, S. F. Gestão Estratégica na Saúde: reflexões e práticas para uma administração voltada para a excelência. São Paulo: látria, 2006.

TANENBAUM, A.S. Sistemas operacionais modernos. 2. ed. São Paulo: Pearson Prentice Hall, 2003.

TEBOL, James. Gerenciando a dinâmica da Qualidade. Rio de Janeiro: Qualitymark, 1991.

TEJON, José Luiz.; XAVIER, Coriolano. Marketing \& Agronegócio: a nova gestão - diálogo com a sociedade. São Paulo: Person, 2009.

VELLOSO, F.C. Informática: conceitos básicos. 7. ed. Rio de Janeiro: Elsevier, 2004.

VIEIRA, Francisco Giovanni David. Marketing Rural: Bases, Vieses e Perspectivas. Disponível em: <https://www.researchgate.net/publication/271766572_Marketing_Rural_bases_vieses_e_per spectivas >. Acesso em: 18 abr. 2020. 